Fecha de recepción: 24 de mayo de 2019

Sugerencia de citación: Parolo, M. P. (2020). El empleo público en Tucumán (Argentina). Ramos, cargos y salarios durante la construcción del Estado provincial (1815-1854). tiempo\&economía, 7(1), 169-209 doi: 10.21789/24222704.1529
Vol. 7 N. ${ }^{\circ} 1$

Enero - Junio del 2020

pp. 169-209
HISTORIA ECONÓMICA, EMPRESARIAL Y DEL PENSAMIENTO

TIEMPO \& ECONOMÍA
DOI:

10.21789/issn.2422-2 704.1529

\title{
El empleo público en Tucumán (Argentina). Ramos, cargos y salarios durante la construcción del Estado provincial (1815-1854)
}

\section{Public Employment in Tucumán (Argentina). Sections, Positions and Wages during the Construction of the Provincial State}

(1815-1854)

María Paula Parolo Profesora de la Facultad de Ciencias Económicas de la Universidad Nacional de Tucumán, Argentina paula_parolo@hotmail.com https://orcid.org/0000-0001-5504-190

\section{RESUMEN}

Este artículo busca examinar el comportamiento de los salarios públicos en una provincia mediterránea enclavada en el noroeste argentino (Tucumán) durante un periodo signado por una coyuntura bélica, altos niveles de conflictividad política y una sostenida crisis económica. A partir de los datos recuperados de las planillas de pago de sueldos de la administración 
provincial, es posible acceder a información cuantitativa y cualitativa sobre salarios de un amplio espectro de empleados estatales, lo cual permite, asimismo, aproximarnos a la composición interna y evolución de la escala salarial en la administración pública provincial durante la convulsionada primera mitad del siglo XIX.

Palabras clave: empleo público, salarios, Tucumán, Siglo XIX, historia económica.

\section{ABSTRACT}

This article seeks to examine the development of public wages in a mediterranean province located in northwestern Argentina (Tucumán) during a period of armed conflict, high levels of political struggles, and a sustained economic crisis. Using data retrieved from the payroll forms of the local administration, it was possible to access quantitative and qualitative information regarding salaries of a wide spectrum of government employees, which also allowed to approach the internal composition and evolution of the salary scale in the provincial public administration during the turbulent first half of the XIX century.

Key words: Public employment, wages, Tucumán, XIX century, economic history. 


\section{PRESENTACIÓN}

Si bien la producción historiográfica sobre la problemática de los precios, salarios y estándares de vida en Latinoamérica ha cobrado un importante impulso en las últimas décadas, la mayor parte de la literatura se concentra en el periodo colonial y en el siglo XX. El problema de las fuentes no constituye un dato menor a la hora de analizar las razones de la escasez de investigaciones que existe sobre la primera mitad del siglo XIX. En efecto, los procesos de independencia y el consecuente periodo de organización nacional latinoamericano (atravesado por la guerra y la sucesión de administraciones de signos opuestos turbadas por las luchas facciosas) trajeron serias consecuencias en términos de conservación, sistematización y archivo de la documentación. En este sentido, la búsqueda y obtención de datos para el periodo en cuestión se torna sumamente dificultosa. A pesar de ello, en los últimos años la historiografía sobre condiciones de vida durante el siglo XIX experimentó un significativo avance tanto a nivel hispanoamericano, en general, como para la Argentina, en particular.

El caso tucumano -una pequeña provincia enclavada en el corazón del actual noroeste argentino- no constituye una excepción respecto a las dificultades para abordar la problemática ya mencionada. Si bien contamos con algunos estudios sobre condiciones de vida durante los últimos años de la Colonia y las primeras décadas posindependientes (Bascary, 1999; Leoni-Pinto, 2001; López-de-Albornoz, 2002; Novillo, 2006; Parolo, 2008) en ellos se abordan cuestiones como las normativas de trabajo, las estrategias de subsistencia, acceso a los recursos y variados aspectos de la vida cotidiana, pero no se indaga específicamente sobre los estándares de vida ni de bienestar de la población. Asimismo, la historiografía local abordó el estudio de precios y salarios, pero para fines del siglo XIX y comienzos del XX, es decir, durante el auge y expansión de la industria azucarera en la provincia.

En suma, para analizar estos temas resulta imprescindible obtener datos sobre precios al consumidor, salarios y canastas de consumos, cuya recopilación constituye todo un reto para el espacio y periodo seleccionado. Si bien en los últimos años se avanzó en esta línea de investigación -especialmente respecto a cuestiones de inequidad, distribución de la riqueza, pautas de consumo, estimaciones de canastas y evolución de los precios (Fandos \& Parolo 2014; Parolo, 2015a, 2016a, 2016b; Parolo \& Fandos 2011)-, el análisis de los salarios y los estándares de vida, empero, son dos importantes aspectos que no han sido abordados en profundidad hasta la actualidad. 
Este artículo constituye, por lo tanto, un avance en este sentido, puesto que se trata de una primera aproximación al comportamiento de los salarios de empleados públicos en Tucumán entre 1815 y 1854. Para ello, se consultaron las planillas de pago de sueldos de la administración provincial asentadas en los libros Mayores y los Manuales de Contaduría de la Tesorería de la provincia de Tucumán (Archivo Histórico de Tucumán, Sección Hacienda). A partir de esta documentación, fue posible acceder a información sobre salarios de un amplio espectro de empleados estatales que inicialmente se hallaban agrupados en tres ramos (sueldos de hacienda, políticos y militares). Con el correr del siglo y del avance del proceso de construcción del Estado provincial, asistimos a una multiplicación de cargos. Así, a los tres ramos iniciales se agregaron los de gobierno, justicia, policía, instrucción pública, imprenta, culto religioso, correos y legislatura. La jerarquía de cargos al interior de cada uno de estos rubros permite, asimismo, aproximarnos a una vasta escala salarial que atraviesa a diferentes sectores sociales urbanos del Tucumán decimonónico.

En ese marco, se elaboró una serie de salarios nominales y reales de los diferentes cargos en el corto plazo y se estimaron las ratios de bienestar de cada una de estas categorías en aquellos años en los que existe información acerca del costo de la canasta alimenticia $(1816,1819,1827$ y 1832).

\section{ESTADO DE LA CUESTIÓN}

La década de 1990 marcó un importante avance de los estudios sobre las independencias americanas del siglo XIX -particularmente las consecuencias económicas del proceso-, los cuales adquirieron mayor relevancia, representada en una multiplicación de publicaciones colectivas e individuales (Allen, Murphy \& Schneider, 2012; Arroyo-Abad, Davies \& Van Zenden 2012; Coastworth, 1992; Maluquerde-Motes, 2013). Así, nuevos actores, nuevas fuentes, nuevas preguntas y nuevos métodos de análisis permitieron reconstruir buena parte de los aspectos económicos de la coyuntura revolucionaria que se hallaban silenciados. En términos generales, los resultados de estas investigaciones advierten que la desarticulación de las estructuras económicas coloniales, así como la marcha de los sucesos políticos y económicos, fueron comunes a toda Hispanoamérica, pero repercutieron de manera diferente en cada uno de los espacios del imperio colonial español. 
Además, en ese mismo marco de renovación historiográfica y revitalización de los estudios económicos, la producción sobre desigualdad y estándares de vida en Latinoamérica cobró un importante impulso durante las últimas décadas. La preocupación de los científicos sociales por la problemática del crecimiento económico moderno y la distribución de la riqueza, así como los debates en torno a las divergencias y convergencias de diferentes regiones en el largo plazo, multiplicaron los estudios sobre precios y salarios; indicadores fundamentales para analizar, directa o indirectamente, los niveles de vida y de desarrollo. Los debates historiográficos surgidos a partir de la confrontación entre estas lecturas sobre el crecimiento económico y el nivel de vida en América Latina, estimularon una vasta producción de estudios de base sobre salarios reales en diversas ciudades del espacio latinoamericano. Investigaciones como las de Llorca-Jaña y Navarrete-Montalvo (2015) sobre Santiago de Chile, Moraes y Thul (2017) sobre Montevideo, Gelman y Santilli (2014a, 2014b, 2016) sobre Buenos Aires, Challú y Gómez-Galvarriato (2015) sobre México, y Riveros (1987) sobre Chile, entre otros, no solo sumaron evidencias empíricas, sino que aportaron nuevas críticas respecto del uso de las variables de análisis.

A pesar de la centralidad del proceso revolucionario en la región y del enorme impacto que supuso el paso de la guerra por las provincias del actual norte argentino, hasta hace unos años la historiografía local no había reparado lo suficiente en sus consecuencias económicas y sociales. Sin embargo, en los últimos años -en sintonía con las remozadas perspectivas de investigación a las que hicimos referencia- se multiplicaron las investigaciones de caso sobre el tema. En este sentido, los avances desde las diferentes provincias dan cuenta de las diversas trayectorias posrevolucionarias que ensayaron cada una de ellas. De este modo, a pesar de los inconvenientes para reconstruir series de salarios en un periodo tan mezquino, en lo que a disponibilidad de fuentes se refiere, la historiografía rioplatense avanzó -con dispar ritmo y resultados según las regiones- en los estudios sobre niveles de vida durante el siglo XIX. A los trabajos pioneros sobre salarios bonaerenses de Johnson (1990) y Barba (1999) se sumaron posteriormente los aportes de Garavaglia (2004) y, más recientemente, las investigaciones de Cuesta (2012), Gelman y Santilli (2014a, 2014b, 2015, 2016, 2018) y Vence-Conti \& Cuesta (2016). Significativos avances sobre la temática se registraron también para Santa Fe (Frid, 2016, 2017; Djenderedjian \& Martirén, 2015a, 2015b, 2016) y Mendoza (Bragoni \& Olguín, 2014). 
El caso tucumano no constituye una excepción respecto a las dificultades para abordar la problemática en cuestión. Tal como lo adelantamos en páginas precedentes, la historiografía local abordó el estudio de precios y salarios para fines del siglo XIX y comienzos del XX (Balán, 1976; Campi, 2004; Correa-Deza \& Campi, 2009; Schleh, 1956). Sobre la problemática específica de los sueldos en Tucumán durante la primera mitad del siglo XIX, el único aporte del que disponemos hasta el momento es un estudio publicado recientemente sobre el poder adquisitivo de los salarios y los niveles de vida de trabajadores calificados y no calificados del ámbito privado en la ciudad de Tucumán entre 1812 y 1833 (Parolo, 2019a).

Conscientes de la necesidad de ampliar el universo social y el arco temporal de análisis para obtener resultados más significativos, este artículo examina la evolución de la escala salarial de los empleados de los diferentes ramos de la administración provincial durante un lapso de 40 años.

\section{FUENTES Y METODOLOGÍA}

Los libros de hacienda de la provincia de Tucumán durante la primera mitad del siglo XIX muestran las falencias propias de la documentación oficial en una época de conmoción política y de coyuntura bélica. Los vacíos de información en algunos años, los cambios en las modalidades en el asiento de la información y la práctica recurrente del pago de haberes "a buena cuenta" (es decir, el pago escalonado y al ritmo de la escasa e irregular disponibilidad de los recursos fiscales), hicieron difícil la obtención de datos fiables respecto de los sueldos mensuales o anuales estipulados para cada cargo en cada año examinado. De allí que el relevamiento de información no se limitó a las planillas de pago de sueldos volcadas en los libros de hacienda (manuales y mayores de contaduría), sino que la búsqueda debió ampliarse a otros fondos documentales, como las escasas reglamentaciones o leyes sobre salarios (sección administrativa), los esporádicos presupuestos anuales del gobierno provincial (actas capitulares del cabildo y actas de la Sala de Representantes) y los libros de Toma de Razón (en los que se registraban novedades de todo tipo en lo que respecta a las cuentas fiscales de la provincia, como los reclamos por deudas impagas, ya sea de empleados o proveedores del Estado).

A pesar de los obstáculos que presentan las fuentes, logramos recopilar salarios mensuales de catorce cargos de las ramas de gobierno (gobernador, ministro, ayudantes, ordenanza y portero), hacienda (tesorero, 
guarda, oficiales, auxiliares, comandante de resguardo, ordenanza) y militar (oficiales, suboficiales y soldados). A partir del haber promedio de cada uno de estos cargos, los agrupamos según una escala salarial de cuatro niveles (o rangos) según su relación con el costo de las canastas de subsistencia y de manutención. A fin de analizar la evolución de los sueldos de cada una de las categorías en el tiempo y su comportamiento relativo, deflactamos los salarios nominales promedio de cada nivel de la escala por el índice de precios del ganado vacuno (principal alimento de la canasta del periodo y único bien del que disponemos de una serie completa y confiable). Finalmente, con el objetivo de estimar ratios de bienestar de cada uno de los segmentos del universo analizado, utilizamos las canastas de subsistencia calculadas para cuatro años del periodo (Parolo, 2015a) y, siguiendo la metodología de Arroyo-Abad (2013), calculamos los cocientes entre los salarios nominales promedio y el costo de las canastas de subsistencia y de manutención, multiplicándolos por 3,25 para así contemplar el consumo familiar. ${ }^{1}$ Este indicador permitió determinar el poder adquisitivo del salario nominal respecto a un nivel mínimo de subsistencia y analizar comparativamente la evolución de los niveles de bienestar y del poder adquisitivo entre los diferentes segmentos salariales durante el periodo bajo estudio.

\section{TUCUMÁN EN EL SIGLO XIX. CONTEXTO SOCIAL, POLÍTI- COY ECONÓMICO}

Desde 1782, Tucumán dependía de la Intendencia de Salta, ubicada al norte del Virreinato del Río de la Plata. Era una ciudad pequeña pero densamente poblada, donde vivían alrededor de 4.000 habitantes. Entre 1811 y 1819 alojó alrededor de 2.000 soldados que se apostaron en ella como retaguardia del Ejército Auxiliar del Perú. En septiembre de 1812 fue el campo de la batalla en la que el general Belgrano doblegó a las tropas realistas que iniciaron su repliegue hacia el Perú. Gracias a la heroica participación de la población tucumana en la guerra, en 1814 se creó por decreto la provincia con el mismo nombre de la ciudad. En 1816 fue elegida sede del Congreso que declaró la Independencia de las Provincias Unidas en Sudamérica, lo que le valió las denominaciones de "cuna de la independencia" o "jardín de la república", que perduran hasta la actualidad.

Sobre la base de estudios previos sobre la estructura socio-ocupacional y la composición de los hogares en el periodo de análisis, que arroja un promedio de 2,5 hijos por familia, multiplicamos el costo de las canastas por 3,25 (dos adultos, dos menores que equivaldrían a un adulto, y medio menor o sea 0,25 adulto). 
Desde la colonia, Tucumán constituyó un nexo que articulaba las relaciones comerciales intra e interregionales, vinculando a la ciudad minera de Potosí con el puerto de Buenos Aires. Tras la crisis producida por la independencia disminuyó el tráfico ascendente de mercadería y la consiguiente provisión de mulas para el transporte de montaña, pero se mantuvieron lazos comerciales con algunas ciudades peruanas.

En el corto plazo, la desestructuración económica producida por la interrupción del tradicional funcionamiento de los circuitos comerciales, la prolongada presencia del Ejército Auxiliar del Norte, el alistamiento de los hombres en las filas del ejército, el elevado costo fiscal de la guerra y la acción demoledora de las tropas, habrían dejado a la economía de la provincia en un estado financiero desesperante, a un importante segmento de las clases mercantiles diezmadas y al stock ganadero prácticamente agotado. Una verdadera "orgía de destrucción de la riqueza colectiva", como calificó Halperín-Donghi al devastador paso de la guerra por las provincias del norte $(2010$, p. 35).

Este panorama desolador pudo ser revertido paulatinamente a partir de la década de 1830, gracias a una política abiertamente proteccionista a favor de las actividades productivas tradicionales, especialmente la explotación ganadera.

A pesar de los inconvenientes que debió enfrentar en las primeras décadas del siglo XIX, el comercio ciudad siguió desempeñando el rol más destacado entre las actividades económicas de Tucumán. Con la llegada del gobernador Alejandro Heredia al poder en 1832, y gracias al reordenamiento político operado por entonces, las transacciones mercantiles recuperaron su ritmo. El circuito de comercialización de mayor intensidad y dinamismo siguió siendo el que se vinculaba con la ciudad puerto, desde y hacia donde los envíos eran regulares todo el año. Así mismo, Córdoba se mantuvo como uno de los principales mercados receptores del tabaco tucumano y los contactos con la región cuyana y las provincias del norte abrieron paso a la entrada de los productos de la provincia en los mercados trasandinos y boliviano, respectivamente.

La diversidad productiva que caracterizó a la economía de la provincia desde la época colonial hasta bien entrado el siglo XIX quedó plasmada en los resultados del censo provincial de 1845, en el que se consignaron como principales rubros la producción de azúcar, aguardientes y productos azucarados, tabaco, otros productos agrícolas (arroz, trigo, maíz, alfalfa, hortalizas 
y legumbres), industria forestal, ganadería y sus derivados. No obstante, a pesar de la diversidad de la que hablamos, esta provincia fue -hasta mediados del siglo XIX-predominantemente ganadera, donde el cuero desempeñó un papel bastante importante debido a sus múltiples usos y destacada comercialización en los circuitos mercantiles que unían a Tucumán con el puerto de Buenos Aires.

La década de 1850, tan notable en transformaciones institucionales, no marcó un cambio sustancial en la vida económica de la región. Sin embargo, ciertas innovaciones como la supresión de aduanas interiores y la reformulación del sistema impositivo de las provincias, entre otras, favorecieron el incremento de las actividades mercantiles y el fortalecimiento de las bases de un proceso de acumulación de capitales que, dos décadas después, fueron claves para la reconversión productiva de la economía tucumana. En este marco de dinamización de los circuitos comerciales y del rol de la ciudad de Tucumán como centro de operaciones comerciales de la región, se observa un marcado crecimiento de las actividades manufactureras y, entre ellas, la azucarera (Campi, 2002, p. 59).

En suma, el comercio se mantuvo durante toda la primera mitad del siglo XIX como la principal actividad económica de la ciudad. Este dominio se tradujo, en el plano de las relaciones sociales, en la hegemonía que los grandes mercaderes mayoristas (comerciantes a "larga distancia") ejercían sobre los minoristas (pulperos y tenderos) y de ambos sobre los productores, quienes de manera conjunta conformaban el sector más dinámico de la economía provincial. Si bien el abasto del mercado local se encontraba de alguna manera supeditado a los mercaderes mayoristas, los bienes de primera necesidad eran producidos dentro de la jurisdicción provincial y comercializados en el mercado (en la plaza principal) o en las pulperías (taberna/almacén de venta al menudeo). Aun así, la dinámica de la circulación mercantil y los mecanismos de abastecimiento y funcionamiento del mercado local no pueden entenderse si no examinamos la cuestión monetaria que emergió como consecuencia de la desestructuración del espacio económico peruano tras el estallido revolucionario.

Por otra parte, en Tucumán coexistían diversos tipos de moneda acuñados por diferentes instituciones e individuos y de variada calidad. En principio, durante los primeros años posteriores a la independencia, circuló la moneda de plata colonial, a la que se sumaron posteriormente la moneda federal, la güemes y la feble. En la documentación del periodo se en- 
cuentran indicios de que la circulación monetaria era muy fluida y su utilización habría permeado varios sectores sociales y actividades económicas. En muchos casos el uso de moneda coexistía con el trueque y el pago diferido basado en un mercado informal de crédito al consumo (consumo a fiado), pero la utilización de metálico no era excepcional y se tomaba como algo cotidiano en muchas instancias del día a día; es decir, el dinero efectivo no solo circulaba entre los sectores mercantiles, sino que también lo hacía con bastante fluidez entre los sectores populares, tanto en las compras al menudeo como en las apuestas de juego, el cobro de salarios, el pago de deudas o empeño de prendas. La "mala" moneda, entonces, no parecía ser un gran problema y, por lo tanto, aparecía mucho más en las transacciones que en la existencia de stocks, relacionada mayormente con la acumulación y la preservación de riqueza (Nicolini \& Parolo, 2009, p. 92).

En este marco, el universo social que alojaba la ciudad de Tucumán era vasto y diverso y se caracterizaba por una estructura social piramidal en cuya cúspide se encontraba una élite claramente definida, constituida tanto por hacendados, agricultores y terratenientes, como por comerciantes mayoristas, pulperos y troperos. En la base de la pirámide también se definían claramente aquellos sectores que compartían la característica de estar ajenos al mundo del prestigio y el poder, quienes trabajaban en relación de dependencia y sobre los cuales recaían las normativas de disciplina social, moral y laboral (peones, jornaleros, criados, sirvientes). El centro de la pirámide se caracterizaba -a diferencia de la cúspide y la base- por una gran heterogeneidad. Pequeños y medianos criadores y labradores, capataces con tareas de mando sobre las peonadas y algunos maestros artesanos de la ciudad presentaban dentro de su heterogeneidad de caracteres y formas de subsistencia un elemento común: contaban con medios (parcelas de tierra, un taller, un pequeño peculio) que les permitía sustentarse sin caer en la dependencia del trabajo asalariado (Parolo, 2008).

\section{LA CONSTRUCCIÓN DE LA ADMINISTRACIÓN PROVIN- CIAL Y LOS CARGOS PÚBLICOS}

En un contexto político y económico tan convulsionado -y por momentos caótico- como el de las primeras décadas del siglo XIX, el Estado provincial se fue construyendo con gran dificultad. La obtención de recursos fue, sin duda, uno de los principales problemas. Las necesidades del Estado provincial durante las diferentes coyunturas bélicas y políticas generaron 
una serie de demandas que determinaron la creación de nuevos ramos en la administración provincial y la multiplicación de cargos en el interior de cada uno de ellos. En efecto, en el transcurso de los casi 40 años aquí analizados, se observa una radical modificación no solo en la nomenclatura sino también en la creación de nuevas dependencias y cargos públicos que fueron acompañados, indefectiblemente, por un mayor gasto en sueldos (ver cuadro 1, anexos).

Durante las tres primeras décadas posrevolucionarias las demandas bélicas colocaron como prioridad a los gastos de guerra $y$, dentro de ellos, a los sueldos militares. La importancia de estos últimos se pone en evidencia si los comparamos con los porcentajes destinados a los salarios de otras áreas, ya que mientras los sueldos militares absorbían $17 \%$ del total de los gastos del erario provincial, el resto no alcanzaban el $10 \%$ por rubro (los sueldos políticos demandaban $7 \%$ de los gastos, los de hacienda $4 \%$ y los otros sueldos $7 \%$ ). Es decir, durante el periodo examinado, los sueldos de la administración provincial importaban alrededor del $35 \%$ de los gastos del fisco provincial.

En 1841 fue elegido gobernador de la provincia el comandante Celedonio Gutiérrez, quien se mantuvo en el poder ininterrumpidamente hasta 1852 gracias -entre otros factores- al tejido de una eficaz red de lealtades militares. Si bien durante su gobierno los gastos de guerra representaron un importante porcentaje de las erogaciones del Estado, estos se redujeron paulatinamente hasta llegar a porcentajes por debajo de $60 \%$. Entre 1848 y 1851 la tendencia fue aún más decreciente (alrededor de $20 \%$ ), acompañada por un notable incremento porcentual de gastos en sueldos no militares. Producto de una profunda reforma fiscal y administrativa, a partir de 1842 se multiplicaron los rubros de gastos en sueldos (al incorporarse los de justicia, policía, instrucción pública, legislatura, etc.) y "desparecieron" de los registros los gastos de guerra y los sueldos militares. En realidad, estos últimos se encuentran registrados, durante ese lapso, bajo un nuevo ramo denominado "gastos de gobierno" u "órdenes del gobierno para objetos", que siguió acaparando el grueso de los gastos provinciales (Parolo, 2016a).

Finalmente, entre 1848 y 1853 se observa cierta regularidad en la clasificación de gastos que se concentraron en siete ramos: (i) sueldos (con un altísimo nivel de desagregación, puesto que aparecen en los listados los sueldos percibidos por cada uno de los funcionarios, desde el gobernador hasta el oficial suplente de tesorería), (ii) gastos de oficina, (iii) gastos de 
culto, (iv) gastos de etiqueta, (v) gastos de guerra, (vi) gastos extraordinarios y (vii) gastos en obras públicas.

En síntesis, la sencilla estructura del gasto público evidenciada en las cuentas de la Hacienda de la provincia durante las guerras por la independencia y primeras décadas de vida independiente (1816-1830), se fue complejizando junto con el proceso de construcción del Estado provincial. En 1831 y 1840 se advierten dos momentos de inflexión en lo que a la estructura de gastos fiscales se refiere. Aunque los gastos de guerra siguieron liderando el esquema de egresos de fondos públicos, las necesidades propias de la construcción de un aparato político-institucional provincial (justicia, policía, gobierno, aduana, etc.) impactaron dicho esquema, con la consecuente multiplicación de ramas y cargos en la administración pública, lo cual redundó en una mayor proporción del presupuesto destinado a estos.

\section{RAMOS, CARGOS Y SUELDOS}

Como se mencionó previamente, entre 1816 y 1839 los sueldos de la administración provincial se limitaban a tres grandes rubros: políticos, militares y de hacienda. A partir de 1840, la proliferación de dependencias, oficinas y cargos multiplicó los tres rubros iniciales al dividir los sueldos políticos entre "Gobierno" y "Secretaría de Gobierno", e incorporarse siete nuevas partidas: justicia, policía, instrucción pública, imprenta, culto religioso, correos y secretaría de la legislatura. A pesar de la propagación de cargos que supuso cada una de estas nuevas dependencias, en este trabajo examinamos solo los tres rubros iniciales (políticos, militares y de hacienda) y solo 14 cargos dentro de ellos, en la medida que revisten continuidad en todo el periodo y permiten construir una muestra (aunque fragmentaria y con cortes temporales) de la evolución de sus salarios.

Entre los sueldos políticos pudimos examinar los cargos de gobernador y el de asesor, secretario o ministro general, cuyos sueldos se encontraban a la cabeza de todas las reparticiones, con un promedio mensual de $\$$ 250 en el primer caso y de $\$ 137$ en el segundo (ver cuadro 2 , anexos). ${ }^{2}$

Los empleados del ramo de hacienda eran más numerosos -probablemente por la acuciante necesidad de fiscalización del cobro de impuestos, fuente casi exclusiva de los ingresos provinciales- y existía una mayor

2 Si bien existían distintos tipos de moneda acuñadas por diferentes instituciones e individuos y de variada calidad, durante los primeros años posteriores a la independencia circuló todavía la moneda acuñada durante el periodo colonial, de allí que todos los precios y salarios aquí referidos están expresados en pesos plata de ocho reales. 
jerarquía de cargos en este, lo que permitió acceder a una escala salarial más desagregada. Encabezaba esta "oficina" el ministro general y/o tesorero, con un salario promedio de \$97. Un escalón por debajo se encontraba el comandante de resguardo (encargado del control de aduanas de la provincia), con una asignación promedio de $\$ 43$, seguido de los oficiales (primero y segundo), que percibían alrededor de $\$ 28,1$ mensuales, los guardas de aduanas, con salarios de $\$ 16$, auxiliares y porteros, cuyas retribuciones alcanzaban tímidamente $\$ 10$ por mes $y$, finalmente, los ordenanzas, con un salario mensual de $\$ 7 .^{3}$

Los sueldos percibidos por cada uno de los grados militares existentes fueron agrupados en tres categorías sobre la base de la clasificación utilizada en los pie de lista y presupuestos de la época: jefes y comandantes (general, coronel y teniente coronel), oficiales (mayor, capitán, teniente y subteniente), suboficiales (sargento, cabo, clarín y tambor) y tropa (soldados). Los sueldos promedios de la cúpula militar (\$ 104,1 mensuales) eran equiparables a los del secretario asesor y del tesorero; el salario de los oficiales (\$ $32,3)$ cercano al de los oficiales de hacienda y los ayudantes de gobierno; los suboficiales $(\$ 7,2)$ ganaban como un ordenanza; y los soldados se ubicaban en la base de la escala salarial $(\$ 6,1)$.

Aunque la muestra obtenida puede resultar poco representativa, considerando que se analizó un universo de empleados "de oficina" que no habría superado los 50 individuos entre los cargos de hacienda y gobierno, los cargos militares otorgan a nuestro recorte un peso relativo nada despreciable. La coyuntura bélica que atravesó todo el periodo de estudio multiplicó las levas forzosas, las cuales convirtieron a una importante proporción de la población masculina económicamente activa en soldados. ${ }^{4}$ Si partimos del censo provincial levantado en 1845, que arrojó la cifra de 3.959 hombres mayores de 14 años residentes en la ciudad, y tomamos el recuento más bajo de uniformados (registrado en 1819, que contabilizaba 300 efectivos en la guarnición de la Plaza), sumado a un promedio de 50 empleados en los ramos de hacienda y gobierno, la representatividad de la muestra alcanzaría un 8,8 \% de la población económicamente activa (PEA) masculina del

Auxiliares, porteros y ordenanzas también son cargos que se encuentran registrados entre los sueldos políticos, los que fueron promediados con los de hacienda.

4 En octubre de 1810, con la I•legada del Ejército auxiliar del Perú a la provincia, se calculaba la presencia de alrededor de 6.000 efectivos entre oficiales y tropa. En 1813, esta cifra se habría reducido a 3.500. En 1816 se estimaba una guarnición compuesta por 1.500 hombres, mientras que en 1819, tras el repliegue del Ejército hacia Córdoba, la plaza militar de la ciudad rondaba los 300 soldados (Parolo, 2015b). 
momento. ${ }^{5}$ Pero más allá de la representatividad cuantitativa de la muestra, la riqueza de los datos obtenidos radica en la amplitud de la escala y las brechas salariales observadas entre las categorías o los diferentes cargos. Nuestro interés está puesto, entonces, en explorar las formas que adoptó la desigualdad en la distribución de los ingresos y en la asignación de recursos en un segmento de trabajadores que, aunque reducido y limitado a la administración pública, nos ofrece datos empíricos suficientes para mensurar la desigualdad entre las disímiles categorías de trabajadores e identificar las tendencias divergentes en lo que a niveles de bienestar se refiere, en una sociedad fuertemente estratificada, como la sociedad tucumana del siglo XIX.

\section{EL COMPORTAMIENTO DE LOS PRECIOS Y EL COSTO DE LAS CANASTAS DE CONSUMO}

No contamos aún con un índice general de precios para el periodo debido a los vacíos de información para la mayoría de los bienes, a excepción del ganado, para el que pudimos construir una serie para el periodo 1816-1854. Para el resto de los bienes alimenticios (maíz, azúcar, arroz, sal y aguardiente) y no alimenticios (leña, carbón, suela, tela, papel) disponemos de series incompletas que, sin embargo, nos permiten observar la tendencia general de los precios durante el periodo de análisis (Parolo, 2016b).

Aunque la evolución de los precios presenta situaciones poco homogéneas debido a que algunos productos se vieron más afectados que otros a raíz de las diferentes coyunturas, es posible advertir una tendencia general en el comportamiento de cada uno de los bienes examinados. Nos referimos a las alzas observadas en casi todos los productos durante los convulsionados años 20 (enfrentamientos interprovinciales a nivel "nacional" y luchas facciosas a nivel provincial), cuyo pico se registró entre 1823 y 1827. Sin duda, la guerra ocupó un lugar destacado en este proceso. El mantenimiento de los ejércitos provinciales supuso un fuerte incremento en la demanda de bienes y servicios e impactó la oferta de bienes agropecuarios debido -entre otros factores- a la "falta de brazos y descuido de campos" por causa del enrolamiento militar. Así mismo, la crisis monetaria implicó dificultades para la circulación de moneda de "buena ley", así como la depreciación y posterior extinción de la moneda Federal en 1824, profundizando los problemas de intercambio comercial. Las cuestiones climáticas colaboraron especialmente en el incremento de los precios agrícolas y ganaderos,

5 Censo provincial ordenado por el gobernador Celedonio Gutiérrez. Archivo Histórico de Tucumán, Sección Administrativa, Vol. 63, Tomo 2, año 1845. 
junto con las prácticas mercantiles de Antiguo Régimen asentadas en la especulación y búsquedas de mejores oportunidades por parte de las clases comerciales, en desmedro del consumidor. Sumado a ello, en un contexto de inestabilidad institucional y confrontación política, las tímidas medidas de control de precios y de abasto de la plaza local no lograron frenar, hasta comienzos de la década de 1830, la tendencia alcista en los precios de productos tanto locales como importados.

Los años 30 del siglo XIX muestran una tendencia a la baja y una relativa estabilidad en los precios, con picos esporádicos y selectivos (1830 en el papel, 1831 en el arroz y el aguardiente, 1833 en la carne) producto de inclemencias climáticas, los enfrentamientos interprovinciales durante los primeros años de la década o de las prácticas mercantiles especulativas. La reactivación de los enfrentamientos armados a comienzos de la década de 1840 (levantamiento de la Liga del Norte contra el gobernador de Buenos Aires, Juan Manuel de Rosas), junto con una etapa de sequías y escasez (entre 1843 y 1847), habrían elevado el nivel de precios del ganado y de los productos agrícolas, sin afectar otros bienes de la canasta de consumo, los cuales mantuvieron una tendencia al descenso. A finales de este periodo (1853), una vez más la guerra, la conflictividad política y la movilización de las tropas, alterarán la economía tucumana, que reaccionó con una nueva alza registrada, principalmente, en el precio del ganado.

En este contexto y en sintonía con el comportamiento de los precios, se observan variaciones en las canastas de subsistencia (alimentos) y de manutención (total). La canasta alimentaria tucumana se conformaba principalmente por el pan y la carne, los cuales, en conjunto, absorbían más del $70 \%$ de los gastos de subsistencia. Las compras de ambos productos eran diarias, junto con la adquisición de la grasa que acompañaba casi indefectiblemente a la carne.

Aunque no para el mismo periodo, estudios sobre otros espacios rioplatenses arrojan resultados similares respecto del tipo de alimentación. Los datos proporcionados por los libros de cuentas del Colegio Apostólico San Carlos Borromeo y del Convento de Santa Ana (Santa Fe) analizados por Carina Frid, dan cuenta de la importancia del pan, la carne y la yerba en la dieta diaria (Frid, 2016). Del mismo modo, en los registros de gastos de los conventos regulares de San Francisco, La Merced, Santo Domingo y de la Compañía de Jesús (también en Santa Fe), se constata la preeminencia del consumo de carne y trigo, que cubrían por sí solos dos mil calorías 
diarias por persona. Junto a ellos, la alimentación se complementaba con grasa, sal, azúcar, yerba y vino (Djenderedjian \& Martirén, 2015a), tal como observáramos para el caso tucumano. A pesar de la particular fertilidad del suelo de Buenos Aires y de su perfil productivo agro-ganadero por excelencia, la canasta alimenticia tampoco se apartaba demasiado del patrón de alimentación de Tucumán o Santa Fe. La carne, el trigo, la grasa y la sal eran, también, los bienes de consumo más frecuentes registrados en los libros de cuentas del Convento Dominico de San Telmo durante el siglo XVIII (Cuesta, 2007). Entre 1810 y 1870, los bienes de consumo básico de la población porteña seguían siendo mayoritariamente la carne y el trigo, a los cuales se sumaban, en menores proporciones, el azúcar y la yerba (Gelman \& Santilli, 2014a).

En resumen, si bien la fertilidad del suelo tucumano permitía una variada producción de frutas, verduras y legumbres, la carne constituía uno de los ingredientes fundamentales de la dieta. ${ }^{6} \mathrm{El}$ azúcar, el arroz, y la sal (que conformaban cerca del $20 \%$ de la canasta alimenticia) se compraban por cantidad (una arroba de azúcar o de arroz, un pan de sal), se almacenaban y se utilizaban fraccionadamente. El maíz, por lo general, era de producción doméstica para el autoconsumo. El aguardiente completaba la dieta y era utilizado tanto como bebida como para curaciones. Con base en esta información, podríamos afirmar que la composición de la canasta alimentaria tucumana se encontraba, sin mayores diferencias, dentro de los patrones de consumo de la época y del espacio rioplatense (Parolo, 2015a).

Además de los alimentos, la ropa y el calzado representaban alrededor del $6 \%$ de los gastos de un consumidor promedio. Se reducían a compras de zapatos, zoquetes, camisas y géneros varios (elefante, bramante, ponteví, lienzo) para la confección de calzones, chaquetas y polleras. Entre otros gastos, se encontraban las velas, el jabón y la leña (13\% de la canasta de consumo), esta última se compraba por carrada o carretada,

6 El análisis de los libros contables del Convento Dominico de Tucumán entre 1815 y 1832, indican que se consumía un promedio de 1,7 kg de carne persona/día, lo que representaba más del $80 \%$ de las calorías diarias ingeridas. Estos cálculos pueden parecer exagerados a la luz de los parámetros de consumo actual de estos alimentos; sin embargo, las fuentes son coincidentes y contundentes en sus referencias al consumo de carne diario. Una de las tantas menciones al respecto alude a las raciones de carne entregadas a soldados estipuladas en medio real por día, lo que importaba -según el precio y el momento del año- entre 3 y 5 libras (1,3 y 2,2 kg, aproximadamente). Así mismo, en 1801, ante una demanda de abastecedores por las matanzas de animales en domicilios, cuya carne se vendía clandestinamente, el Cabildo estipuló que en casa de familia la matanza peculiar no exceda las 6 a 8 reses que indica el abasto anual. Es decir, se estimaba un promedio de 7 reses para alimentar a una familia en un año. Si ensayamos una serie de cálculos a partir de los indicios que nos brinda esta fuente, podemos afirmar que se estimaba un consumo promedio de $1 \mathrm{~kg}$ de carne persona/día (Parolo, 2019b). 
observándose una mayor frecuencia de compras durante los meses de invierno (Parolo, 2015a).

El análisis desagregado de las canastas de consumo en cuatro momentos del periodo abordado no arroja cambios sustantivos en su composición. El predominio del consumo de la carne y del pan se mantiene en los cuatro casos. Asimismo, la composición de la canasta total tampoco muestra demasiadas variaciones. Los resultados del análisis comparativo entre las canastas obtenidas para 1815, 1819, 1827 y 1832 permitirían afirmar, entonces, que en el transcurso de las tres primeras décadas posindependientes los hábitos, niveles y estructura del consumo no habrían presentado modificaciones de peso. Lo que sí sufrió cambios -como ya lo adelantáramos- fue el costo de las canastas, el cual disminuyó paulatinamente a medida que avanzaba el medio siglo. Mientras que en 1815 una unidad familiar necesitaba $\$ 17,06$ para cubrir la canasta alimenticia y $\$ 23,15$ para la manutención general, en 1832 el costo disminuyó a \$ 8,53 y \$13,40 respectivamente (ver cuadro 4, anexos).

\section{RATIOS DE BIENESTAR Y NIVEL ADQUISITIVO}

A partir de los datos sobre precios y costos de consumo del periodo, agrupamos los salarios de los empleados del Estado en cuatro categorías (ver cuadro 3, anexos). La más baja corresponde a aquellos cargos con baja calificación, cuyas retribuciones se encontraban por debajo del nivel de subsistencia (porteros, ordenanzas, suboficiales y soldados), en tanto sus salarios se encontraban entre $\$ 5$ y 12 ; en promedio $\$ 7,1$, poco más que la mitad de la canasta alimentaria familiar, la cual ascendía a \$13,4). Por encima de ellos, agrupamos los sueldos que alcanzaban a solventar la canasta básica para un grupo familiar. Ayudantes, guardas y auxiliares (de gobierno y de hacienda) percibían un salario promedio de $\$ 13,2$ que llegaba a cubrir la alimentación mensual de una familia. En un tercer nivel agrupamos los sueldos que superaban el costo de manutención total de una unidad familiar (calculado en $\$ 18,2$ ) ya que sus ingresos se encontraban entre $\$ 20$ y 40 mensuales (comandante de resguardo, oficiales del ejército). El escalafón más alto, correspondiente a gobernador, ministros y jefes militares, superaba holgadamente los costos de subsistencia y manutención. Los salarios de este segmento de empleados públicos equivalían a cuatro sueldos del escalón inmediatamente anterior, a 11 del siguiente y a 21 sueldos de los empleados de menor calificación. 
A pesar de lo anterior, las brechas entre las cuatro categorías salariales antes descritas no se mantuvieron constantes durante los casi cuarenta años examinados. Si desagregamos por año la proporción entre los sueldos de mayor rango y los de las otras tres categorías salariales (ver cuadro 5, anexos), advertimos que la relación entre los sueldos de las dos primeras categorías (autoridades político-militares/funcionarios, oficiales del ejército) no experimentó variaciones significativas entre 1816 y 1854 (se mantuvo entre 3,9 y 5,9 ). Por el contrario, la equivalencia entre los ingresos de los primeros y las tercera y cuarta categorías (auxiliares y suboficiales/porteros, ordenanzas, suboficiales, soldados) sufrió un paulatino alejamiento a partir de 1823 , marcando un pico máximo en 1842/44, años en los que el salario de la cúpula dirigente superaba 34 veces el de un empleado de menor rango.

Las curvas de los salarios nominales de las diferentes jerarquías de empleados públicos (gráfica 1a) permiten observar que si bien a las dos primeras categorías las separaba una gran distancia salarial, estas siguieron una tendencia similar a la baja entre 1815 y 1819 y una suerte de meseta o leve incremento en los años 20. En los años 30 y 40, empero, sus ritmos se diferencian, mostrando la primera categoría un marcado ascenso (cuyo pico se observa en 1844, con el máximo promedio salarial de $\$ 171,7)$ y luego un leve descenso en 1852 (a $\$ 161$ ). El dibujo de la curva del segundo rango de funcionarios públicos, por el contrario, desciende entre 1826 y 1844 (a $\$ 29,1)$ y se recupera levemente en $1852(\$ 35,5)$. El movimiento entre ambas curvas vuelva a sintonizarse luego de ese año, notándose una tendencia decreciente que toca el punto más bajo del periodo analizado (\$ 127 en la primera categoría y $\$ 25,1$ en la segunda).

Gráfica 1 a.

Evolución de los salarios nominales por categorías de empleados (I)

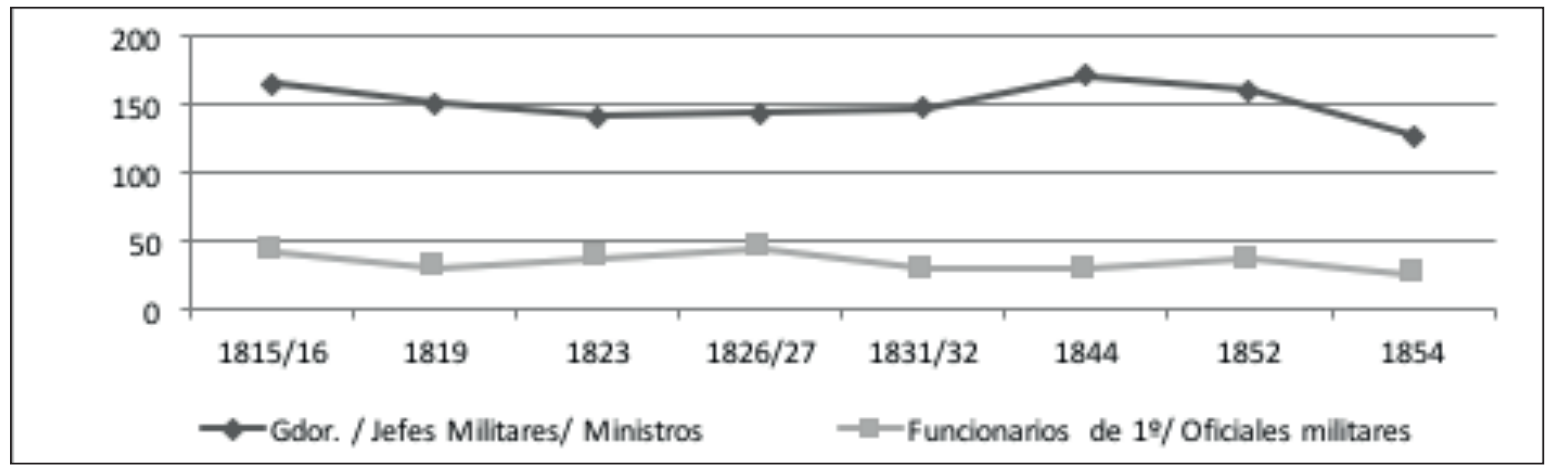


Gráfica 1 b. Evolución de los salarios nominales por categorías de empleados (II)
Del mismo modo, los dos rangos inferiores de empleados públicos presentan movimientos divergentes (gráfica 1b); aunque parten de valores muy próximos en 1815 ( $\$ 13$ los ayudantes, guardas y auxiliares y $\$ 12,2$ porteros, ordenanzas, etc.). A partir de 1819, los salarios de ayudantes/guardas/auxiliares se alejan de la tendencia a la baja registrada en los porteros y ordenanzas y el movimiento de la curva toma un carácter errático al marcar un abrupto descenso en 1823 (año de crisis y suba generalizada de precios en Tucumán), una también abrupta (y extraña) ${ }^{7}$ recuperación en 1826, un nuevo descenso en los años 30, una meseta en los 40 y una recuperación en 1852 que se mantiene hasta 1854. La última categoría, por el contrario, registra un claro descenso del salario hasta 1844. A partir de 1852 la curva asciende ligeramente, sin recuperar el nivel de 1815, año que registró el salario máximo de todo el periodo $(\$ 12,2)$ para el rango más bajo de empleados del Estado.

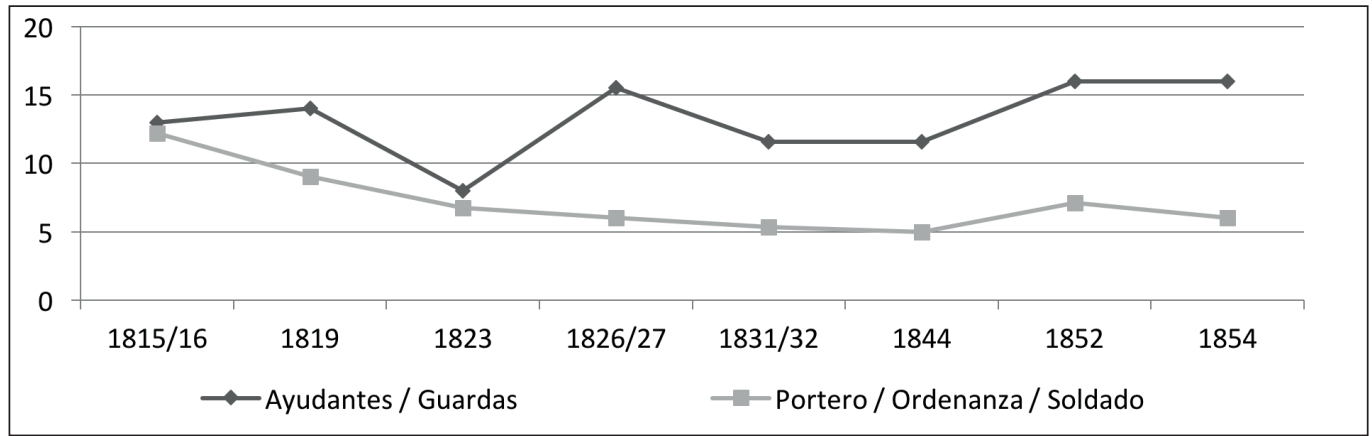

Fuente: Archivo Histórico de Tucumán (AHT). Sección Hacienda (SH). Planillas de pago de salarios. Libros de Contaduría (Mayores y Manuales), años 1816-1854
Si incorporamos al análisis el impacto de los precios sobre los diferentes rangos salariales (gráficas $2 a$ y $2 b$ ) ${ }^{8}$ las brechas entre las categorías se acentúan, pero los movimientos de las curvas se correlacionan. Con diferentes grados de intensidad en sus alzas y bajas, los salarios reales de las cuatro categorías de empleados públicos muestran a comienzos del periodo (década de 1810, signada por la conmoción de la guerra y suba de precios) salarios iniciales relativamente altos $y$, posteriormente, una tendencia decreciente (mucho más acentuada en los extremos, es decir, en

7 Resulta extraña esta alza de salarios, puesto que se trata de años críticos en la economía tucumana, en los que ninguna de las otras categorías registra aumento de sueldo. Posiblemente, pueda tratarse de errores de registro de la fuente.

8 Para estimar los salarios reales se utilizó el índice de precios de la res (base $100=$ año 1815) ya que no disponemos de un índice general de precios para el periodo. La única serie de precios completa y confiable es la del ganado vacuno. Esta decisión metodológica se respalda en la importancia de la carne en la dieta tucumana, que representaba más del $50 \%$ de los gastos en alimentación (Parolo, 2016b, pp. 119-120) 
la primera y cuarta categorías de empleados). En los años 20 (atravesados por enfrentamientos facciosos y fuertes incrementos de precios), los salarios reales de todas las categorías se desploman, para luego recuperarse notablemente durante la década de 1830, etapa de estabilización política y de reordenamiento de la administración provincial; proceso acompañado de una significativa baja de precios, especialmente de la carne. Promediando los años 40, los salarios reales experimentaron un nuevo descenso producto de la reactivación de los enfrentamientos armados y de una etapa de sequías y escasez que habrían elevado el nivel de precios. A partir de entonces, los salarios se mantienen relativamente estables hasta 1854. La excepción se encuentra en la evolución de los salarios reales de la tercera categoría (gráfica 2b), en la que observamos un comportamiento diferente, marcado por una abrupta caída entre 1819 y 1823, así como una Ilamativa subida a final del periodo (1852-1854).

Gráfica 2a.

Evolución de los salarios reales por categorías de empleados (I)

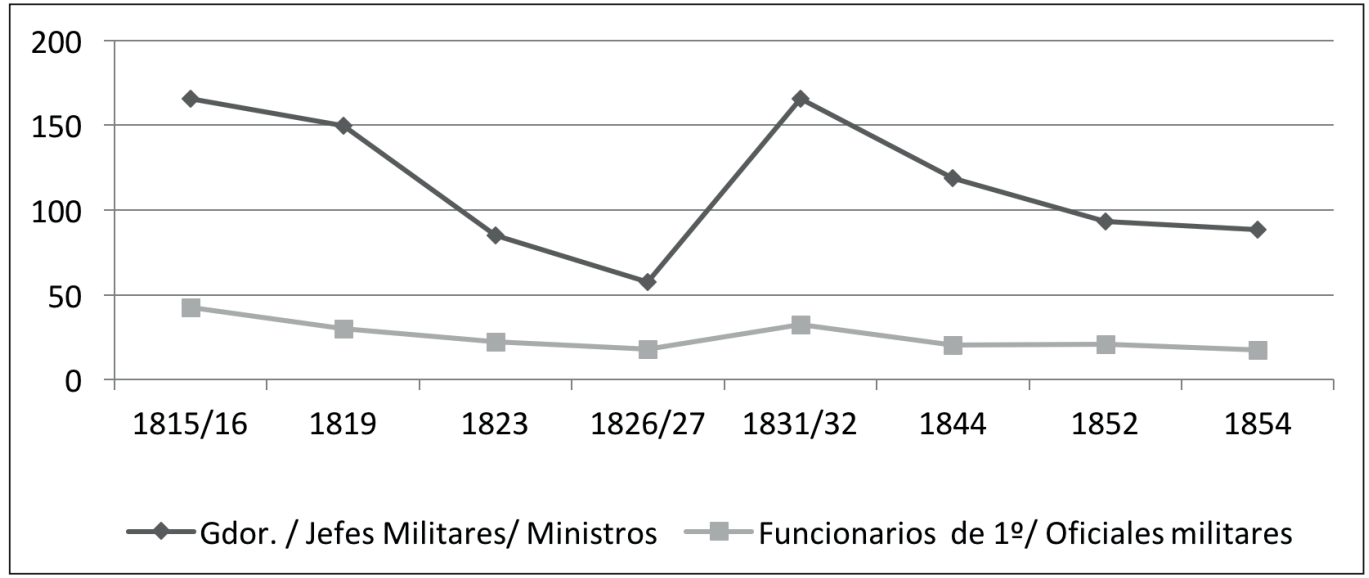

Por lo hasta aquí analizado, es posible inferir que el comportamiento de los precios afectó de manera disímil los niveles de bienestar y la capacidad adquisitiva de los trabajadores del Estado. En efecto, si examinamos los resultados de las ratios de bienestar obtenidos para cada una de las categorías en cuatro cortes temporales del periodo, ${ }^{9}$ es posible advertir la distancia entre las diferentes categorías salariales y la ampliación o reducción de brechas según el momento y el rango del que se trate (gráfica 3).

9 Los welfare ratios (WR), o niveles de bienestar, se estimaron a partir de la definición de las canastas mínimas de supervivencia (alimentos) y la canasta total o respetable (alimentos más otros bienes básicos como lumbre, vestido, combustible, alquiler) para una familia de cuatro individuos (dos adultos y dos niños) y su relación con los ingresos (salarios nominales/costo canastas). Es decir, se calculó cuántas canastas se podían comprar con los salarios de las diferentes categorías de empleados. Se estimó, de este modo, una suerte de "capacidad adquisitiva" de los distintos rangos salariales en diferentes momentos del periodo, lo que permitiría mensurar la desigualdad entre salarios e identificar las tendencias (convergentes y/o divergentes) en lo que a niveles de bienestar se refiere.
Fuente: Archivo Histórico de Tucumán (AHT). Sección Hacienda (SH). Libros de Contaduría (Mayores y Manuales). Planillas de pago de salarios y de gastos de guerra (precios de reses), años 1816-1854. 
Gráfica 2b.

Evolución de los salarios

reales por categorías de empleados (II)

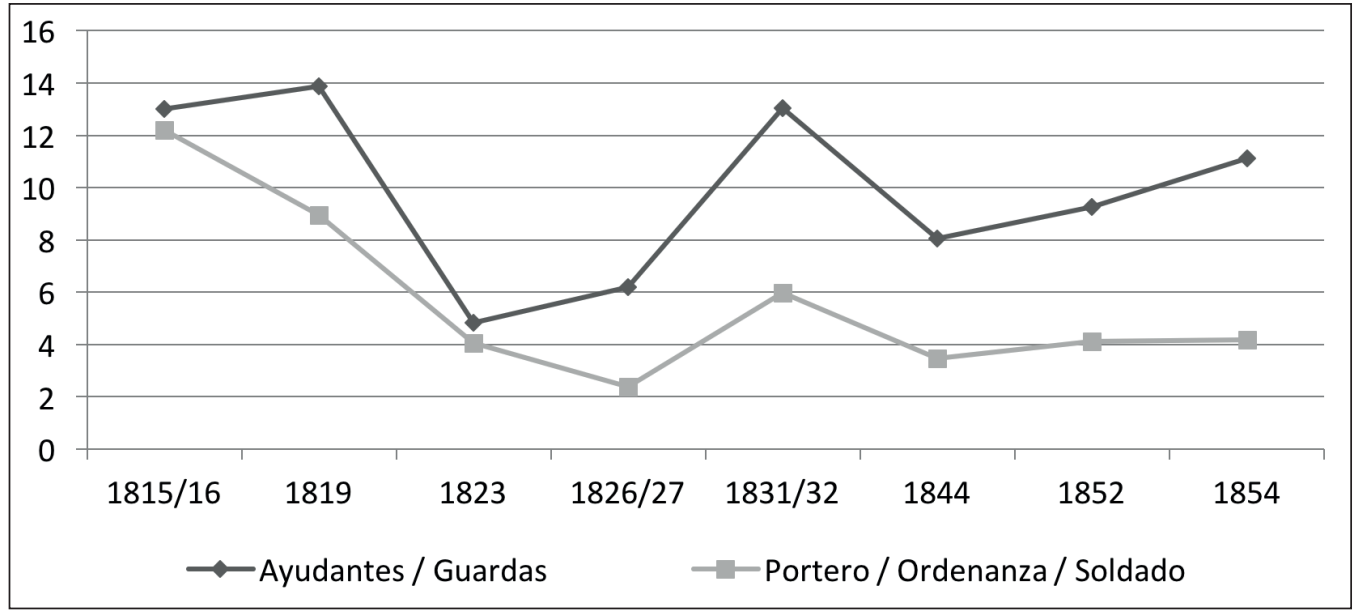

Fuente: Archivo Histórico de Tucumán (AHT). Sección Hacienda

(SH). Libros de Contaduría

(Mayores y Manuales). Planillas

de pago de salarios y de gastos

de guerra (precios de reses), años 1816-1854.

\section{Gráfica 3.}

Ratios de bienestar por etapa según categoría salarial (canasta alimenticia)

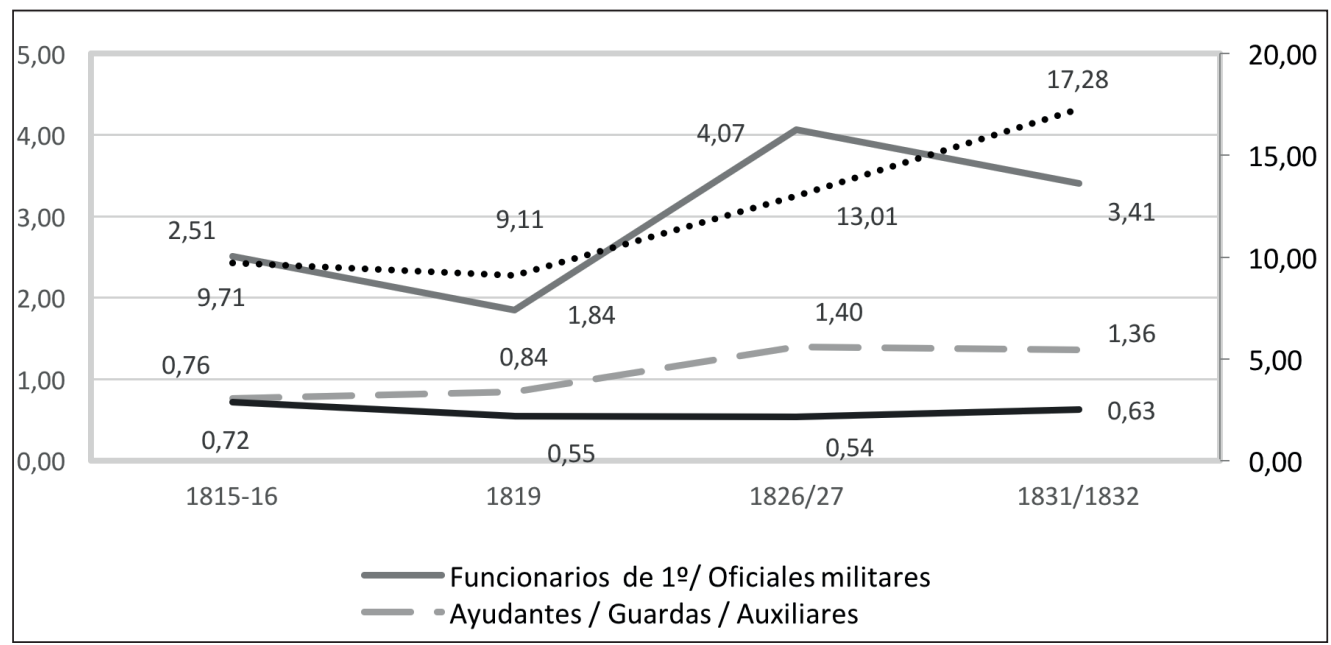

Fuente: Archivo Histórico de Tucumán (AHT). Sección Hacienda

(SH). Planillas de pago de salarios. Libros de Contaduría (Mayores

y Manuales). Años 1816-1854 y Archivo Domiciano de Tucumán.

Libros de Procura, Tomo I

$$
\text { (1781-1876). }
$$


La gráfica 3 permite apreciar las distancias entre los rangos salariales, en lo que respecta a su capacidad adquisitiva, durante el transcurso de las tres primeras décadas del siglo XIX. La primera de las categorías salariales, correspondiente a los altos cargos de la administración provincial (línea punteada trazada sobre el eje secundario del gráfico), se encuentra a una gran distancia del resto, en tanto registra ratios de bienestar que superan entre nueve (en 1816 y 1819) y 17 veces (en 1831-1832) el costo de la canasta alimenticia del periodo. Aunque la curva que arrojan los welfare ratios (WR) -también conocidos como niveles de bienestar- de la segunda categoría (en la que agrupamos funcionarios de primer rango y oficiales militares) se encuentra muy alejada de la de los gobernadores y ministros. Esta categoría se mantuvo durante todo el periodo por encima del costo de la canasta, es decir, su poder adquisitivo fluctuó entre un mínimo de dos canastas (en 1815-1816 y 1819) y un máximo de cuatro canastas (1826). En ambos casos, si bien experimentaron leves descensos en 1819 , sus ratios se recuperaron en las décadas subsiguientes, superando ampliamente los niveles de bienestar registrados para 1815.

La curva de la tercera categoría (correspondiente a ayudantes, guardas y auxiliares) arroja resultados diferentes. En los dos primeros registros (1815 y 1819), los ingresos salariales no lograron cubrir el costo de la canasta alimenticia de un núcleo familiar (con ratios de 0,76 y 0,84, respectivamente); situación que se revierte recién en los cortes de 1826 y 1832, años en que superan en 1,40 y 1,36, respectivamente, el costo del nivel de consumo de subsistencia. El escalafón más bajo de la escala salarial (porteros, ordenanzas, suboficiales, soldados) es el que exhibe un deterioro significativo durante todo el periodo examinado, con una ratio promedio de 0,54 , lo cual indica que el salario nominal de estos empleados no alcanzaba para adquirir la mínima cantidad de productos para mantener a un grupo familiar. La leve mejoría que presenta el indicador a comienzos y a final del periodo (con ratios de 0,72 y 0,63 , respectivamente), no fueron suficientes para alcanzar el costo mínimo de subsistencia del momento. Este desempeño disímil de los niveles de bienestar entre las diferentes categorías de asalariados se profundiza aún más si examinamos su capacidad adquisitiva general, utilizando como referencia el costo de la canasta total de manutención, es decir, alimentación, vestimenta, combustible. 
TIEMPO \& ECONOMÍA

Vol. 7 N. ${ }^{\circ} 1$ | Enero - Junio del 2020

pp. $169-209$

En la primera categoría (gráfica 4) resulta más que evidente la tendencia creciente de la capacidad adquisitiva de ambas canastas durante todo el periodo. En el caso de la segunda categoría (gráfica 5), si bien el poder adquisitivo se mantuvo por encima del costo de la canasta de consumo general, se observa un movimiento inestable del indicador con notables retrocesos en 1819 y 1831/1832 respecto a las mediciones inmediatamente anteriores. Por su parte, el tercer escalafón (gráfica 6) también muestra una tendencia creciente -aunque más suavizada que la que se observa en las curvas precedentes-, registrando una ínfima mejora entre uno y otro año. Sin embargo, sus salarios no alcanzan a cubrir el costo de la canasta total en ningún momento.

Gráfica 4. Evolución de la capacidad adquisitiva (canasta alimenticia y total)

Fuente: Archivo Histórico de Tucumán (AHT, Sección Hacienda (SH), Libros de Contaduría (Mayores y Manuales), planillas de pago de salarios (1816-1854) y Archivo Domiciano de Tucumán, Libros de Procura, Tomo I (1781-

1876).

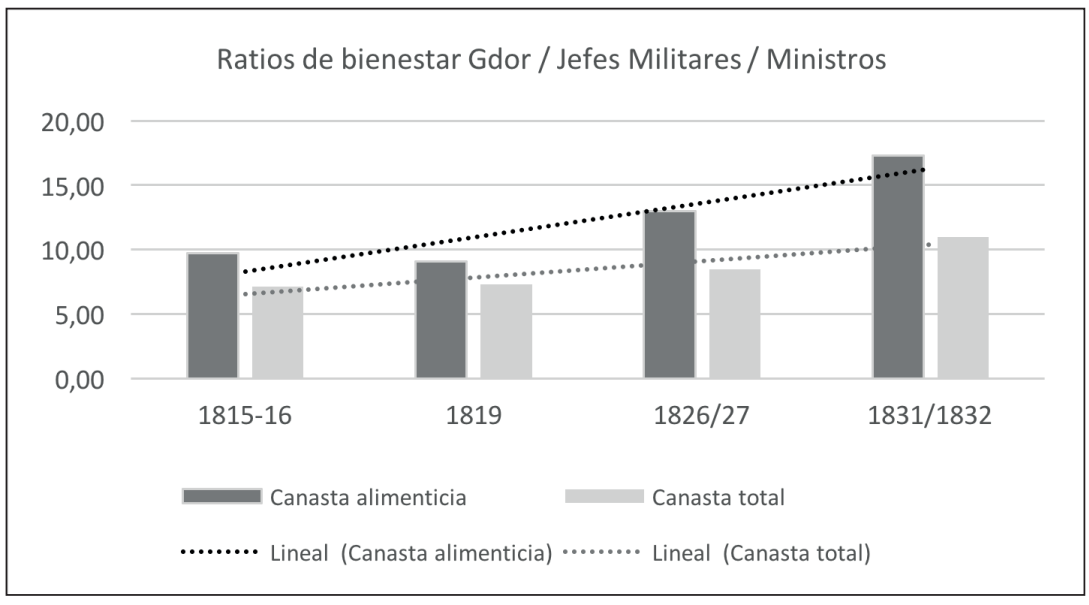

Gráfico 5. Evolución de la capacidad adquisitiva (canasta alimenticia y total)

Fuente: Archivo Histórico de Tucumán (AHT, Sección Hacienda (SH), Libros de Contaduría (Mayores y Manuales), planillas de pago de salarios (1816-1854) y Archivo Domiciano de Tucumán, Libros de Procura, Tomo I (1781-

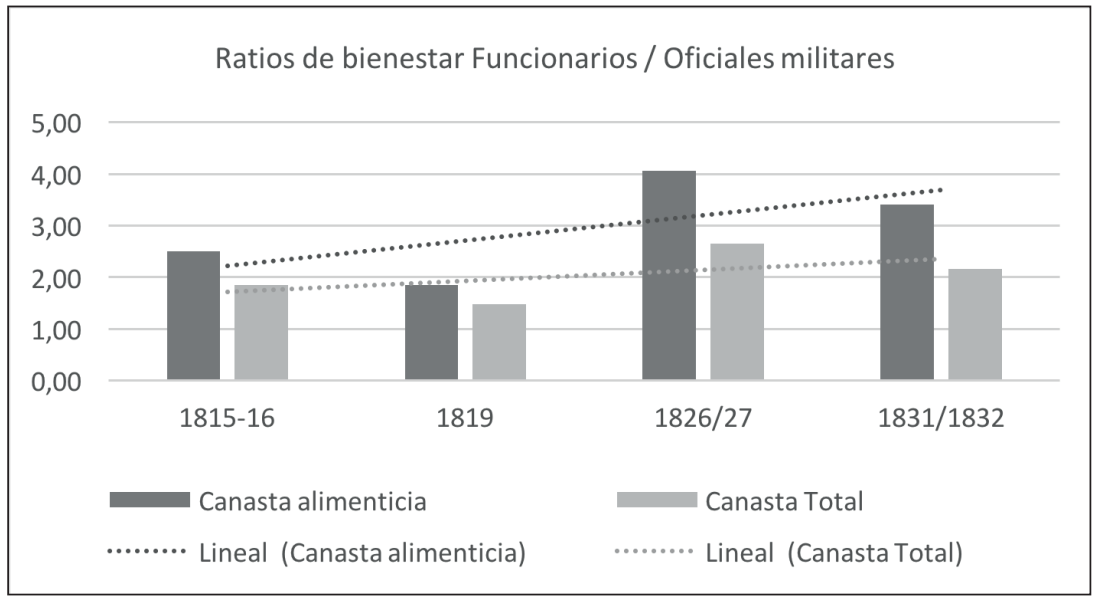




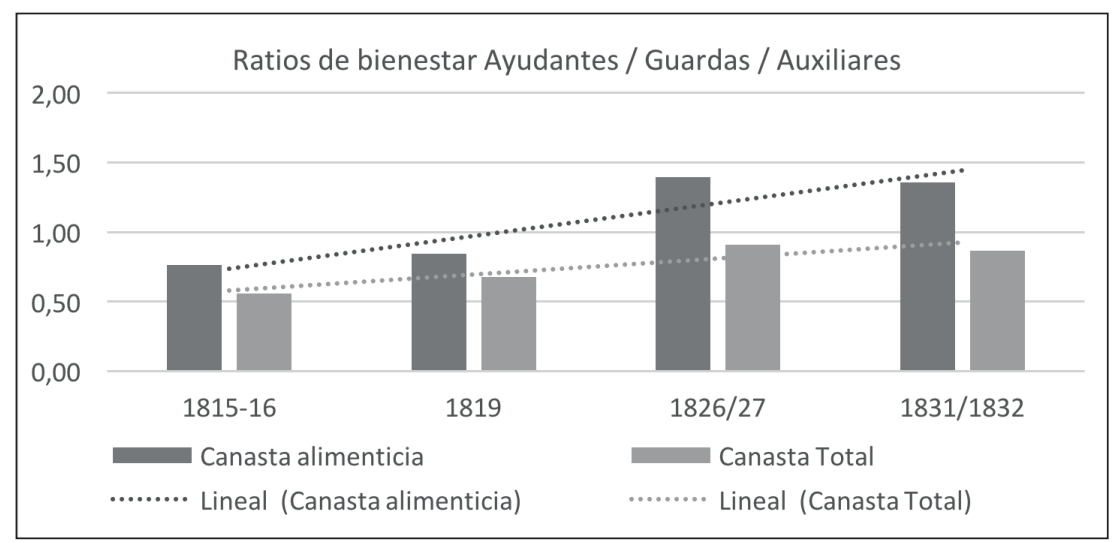

Por último, las ocupaciones menos calificadas, en contraste con las tendencias observadas en las tres categorías de salarios analizadas anteriormente, registran una paulatina depreciación de su capacidad adquisitiva de la canasta total. En 1815, el salario promedio de un portero, ordenanza o soldado alcanzaba para cubrir solo media canasta $(W R=0,53)$, su capacidad de compra descendió a 0,44 en 1819, se desplomó a 0,35 en 1826/1827 y se mantuvo en 0,40 en 1831/1832 (gráfica 7).

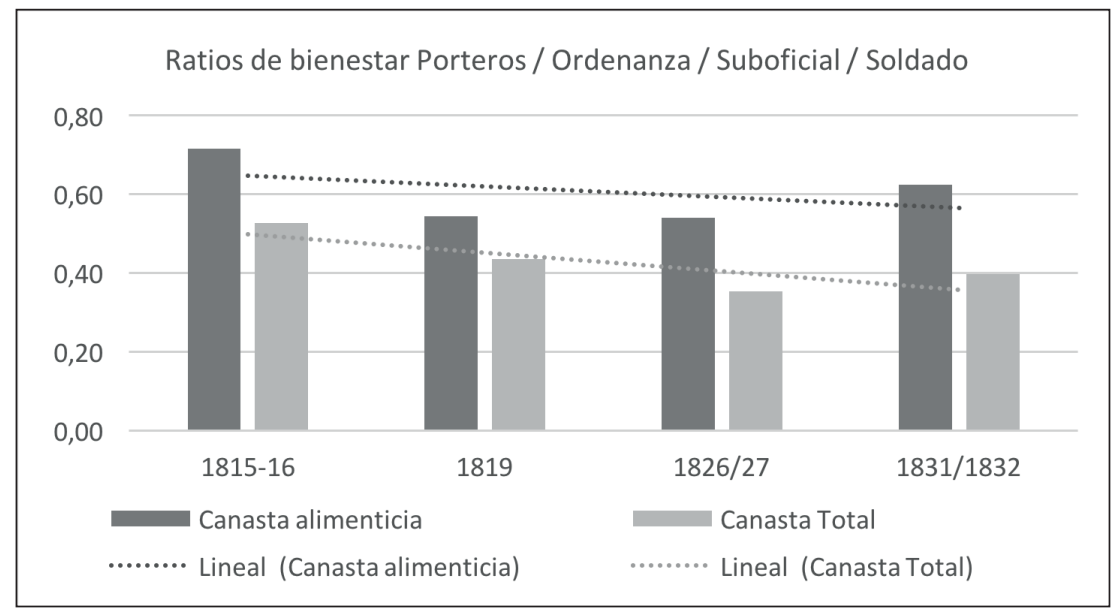

\section{LOS SUELDOS DE LOS EMPLEADOS PÚBLICOS EN PERS- PECTIVA COMPARADA}

A pesar de que la problemática en torno a los salarios urbanos en Tucumán no ha sido aún analizada de manera completa para el periodo que nos ocupa, un estudio reciente sobre las retribuciones a peones jornaleros de la construcción en el convento de Santo Domingo (Parolo, 2019a) arroja algunos datos que permiten poner en perspectiva comparada los resultados

\section{Gráfica 6.}

Evolución de la capacidad adquisitiva (canasta

alimenticia y total)

Fuente: Archivo Histórico de

Tucumán (AHT, Sección Hacienda (SH), Libros de Contaduría

(Mayores y Manuales), planillas de pago de salarios (1816-1854) y Archivo Domiciano de Tucumán, Libros de Procura, Tomo I (17811876).

\section{Gráfica 7.}

Evolución de la capacidad adquisitiva (canasta alimenticia y total)

Fuente: Archivo Histórico de Tucumán (AHT, Sección Hacienda (SH), Libros de Contaduría (Mayores y Manuales), planillas de pago de salarios (1816-1854) y Archivo Domiciano de Tucumán, Libros de Procura, Tomo I (17811876). 
hasta aquí obtenidos. El análisis de los datos proporcionados por las fuentes conventuales indica que el salario nominal promedio de un peón de albañil rondaba los $\$ 6$ mensuales. Puesto en escala con las retribuciones nominales percibidas en la administración provincial (ver cuadro 3, anexos), se advierte que estamos ante un segmento de trabajadores cuyos ingresos se encontraban por debajo de los percibidos por el escalafón más bajo de empleados del Estado (ordenanzas, porteros, suboficiales y soldados), quienes percibieron entre 1815 y 1832 un sueldo nominal promedio de $\$ 7,1$ mensuales.

Si observamos el comportamiento de los ingresos de los peones urbanos en las tres primeras décadas del siglo XIX (gráfica 8), la curva indica que, a pesar de una aparente tendencia de los ingresos de los peones a mantenerse sobre la media (\$ 5) y de las esporádicas y leves subidas, los salarios nominales habrían descendido 31 \% en todo el periodo. Puestos en paralelo con los sueldos del escalafón más bajo de la administración provincial, se advierte que estos últimos experimentaron un deterioro mucho más significativo. Al inicio de la serie los salarios de la cuarta categoría de empleados estatales (porteros, guardas y soldados) triplicaban el valor de los salarios de peones, sin embargo, a medida que avanza el tiempo, la brecha entre ambos disminuye hasta igualar sus ingresos con los de peones urbanos en 1831/1832.
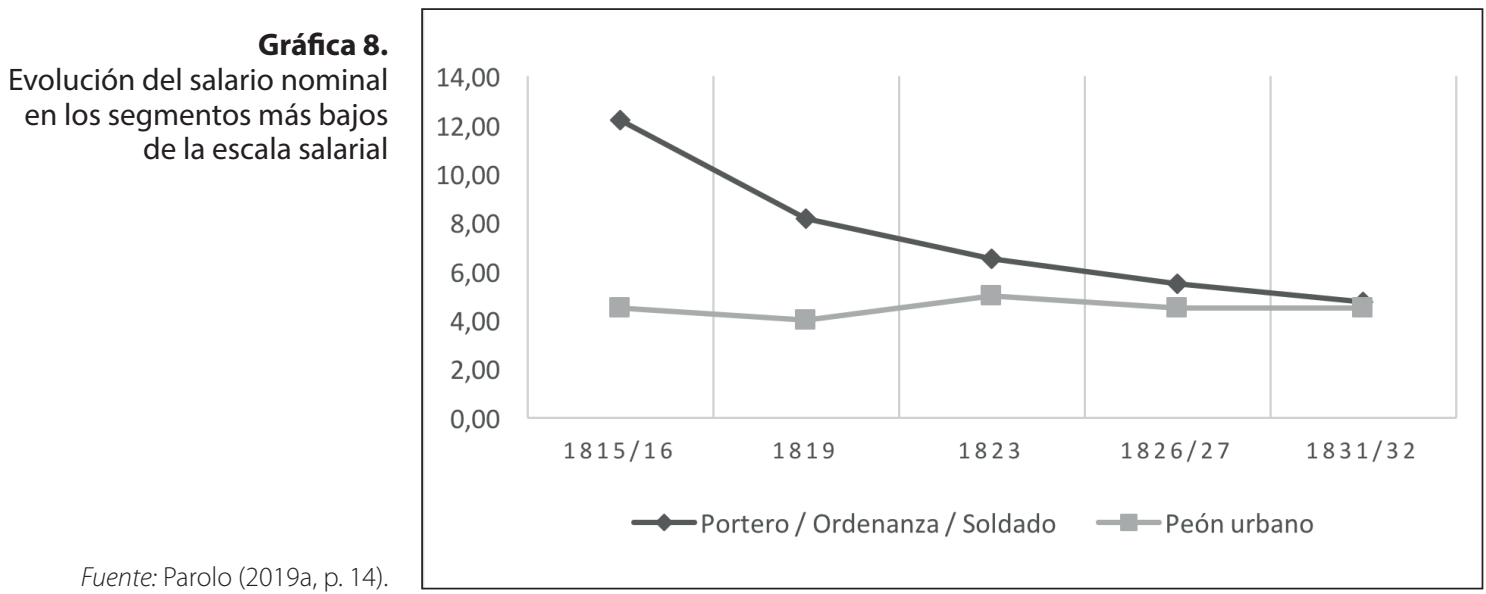

Un movimiento similar, pero mucho más abrupto, dibuja la curva de salarios reales, que, si bien acompañó el comportamiento de los salarios nominales, muestra mayor proximidad entre ambas curvas desde mediados de los años 20 (gráfica 9).

En definitiva, los datos sobre salarios de peones albañiles urbanos abonan la hipótesis que adelantáramos sobre el impacto divergente de las coyunturas económicas por las que atravesó la provincia sobre los diferentes 
segmentos de asalariados. Tanto los empleados públicos de baja o nula calificación como los peones-jornaleros, registraron un franco deterioro en sus salarios (nominales y reales) hasta finales de los años 20, así como una leve recuperación al despuntar la década del 30 . No obstante, el movimiento de ambas curvas marca claras diferencias de ritmo e intensidad.

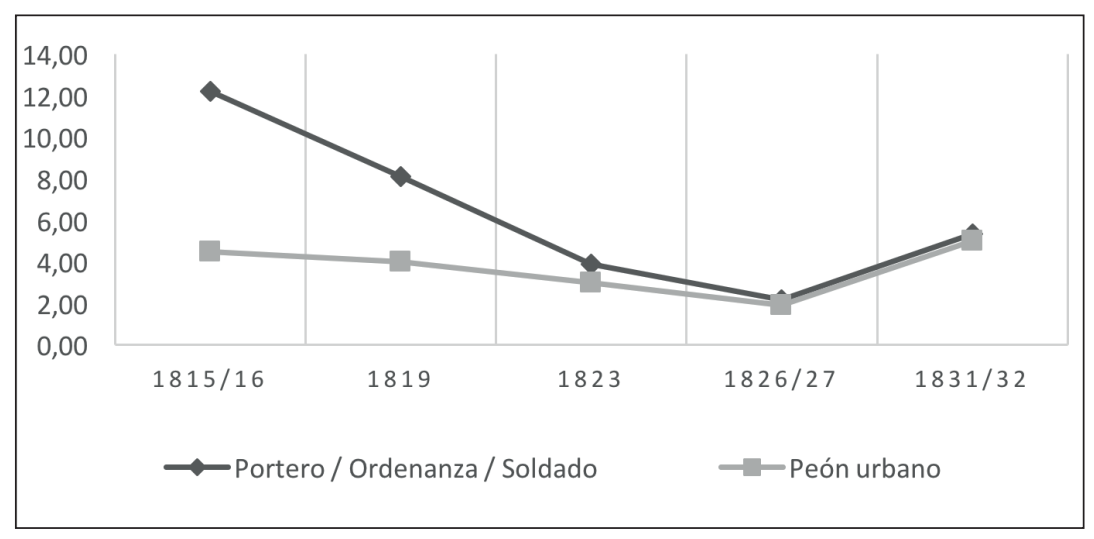

Mientras los porteros, ordenanzas y soldados experimentaron una abrupta caída de sus ingresos entre 1815 y 1827, los ingresos reales de los peones albañiles fueron disminuyendo de manera paulatina. Puesto en términos de niveles de bienestar (es decir, cantidad de canastas que podían adquirir las diferentes categorías de trabajadores examinadas), constatamos una vez más la vulnerable situación que compartían los empleados del escalafón más bajo de la administración y los peones de la construcción. Si bien la capacidad adquisitiva de este segmento laboral parece haber aumentado entre comienzos y finales del periodo examinado, no alcanzó a cubrir más de media canasta alimentaria y un tercio de la canasta total de un grupo familiar promedio.

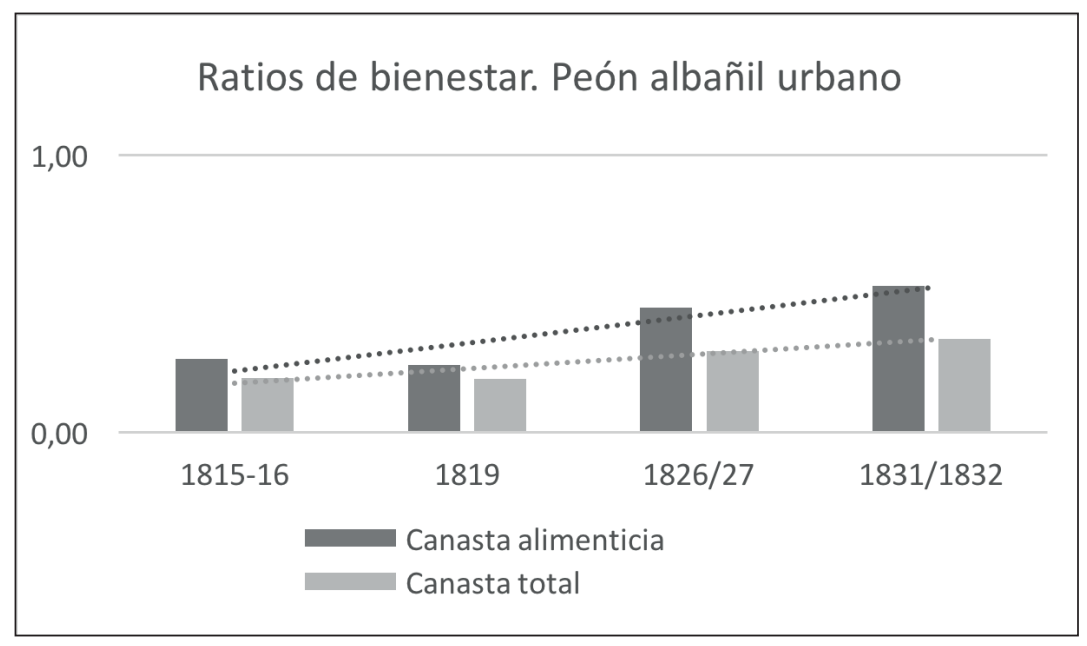

Gráfica 9.

Evolución del salario real en los segmentos más bajos de la escala salarial

Fuente: Parolo (2019a, p. 14).

\section{Gráfica 10.}

Evolución de la capacidad adquisitiva (canasta alimenticia y total 
Ordenanzas, porteros, soldados y peones se encontraban, entonces, por debajo de toda capacidad de manutención de una unidad familiar. Se impone, en este punto, el interrogante en torno a cómo logró el segmento peor remunerado del mundo laboral hacer frente al sostén de una familia. Si bien solo un abordaje más amplio de la dinámica y fuentes de ingresos de la economía doméstica familiar podría darnos la respuesta, es posible ensayar una hipótesis tentativa asociada al perfil social de estos trabajadores que, en su amplia mayoría, eran hombres jóvenes y solteros, por lo que es factible suponer que las retribuciones que percibían eran suficientes para la subsistencia personal. En efecto, si aplicamos el cálculo de las ratios de bienestar sobre la canasta per cápita, resulta que los empleados públicos de más bajo rango alcanzaban a cubrir más de dos canastas en los primeros años del periodo, mientras el salario de un peón no llegaba a cubrir ni siquiera una. Recién a fines de la década del veinte y comienzos de la del treinta, los ingresos de los peones alcanzaban para más de una canasta de subsistencia. Trasladando el análisis a la adquisición de la canasta total de bienes, la brecha sigue manteniéndose en la medida que los empleados estatales peor remunerados (portero, soldado, etc.) logran cubrir más de una canasta en todos los cortes temporales examinados, mientras que los sueldos de los peones cubren tan solo la mitad de ella en 1815 y 1819, y alcanzan tímidamente a cubrirla recién en 1831 (Parolo, 2019a, p. 15).

En otro plano de análisis, resulta interesante poner en perspectiva comparada los resultados obtenidos para el caso tucumano con los de otros espacios rioplatenses. Los estudios de Gelman y Santilli sobre salarios y desigualdad en la provincia de Buenos Aires entre 1810 y 1870, permiten advertir que la importante distancia entre el salario del oficial y el de suboficiales y soldados que encontramos en Tucumán se replicaba también en el caso bonaerense. Además de esta brecha (que se mantuvo durante todo el periodo), los salarios militares en Buenos Aires también se desploman hacia 1826, producto de la desvalorización del papel moneda que, evidentemente, afectó a todas las provincias del Río de la Plata (Gelman \& Santilli, 2014a, p. 102).

En los años 30, los salarios se recuperan tanto en uno como en otro espacio, producto de la baja de precios que parece, también, haber sido generalizada. La comparación entre salarios militares y los del peón rural arrojan algunas similitudes con el comportamiento y relación entre salarios que observamos en Tucumán entre la categoría más baja de empleados estatales (en la que suboficiales y soldados ocupan un lugar mayoritario) y los peones 
urbanos (gráficas 8 y 9). En ambos casos, se observa que a comienzos del periodo (1810-1820) los salarios militares estaban a significativa distancia (por encima) de los de los peones, producto, probablemente, de la extrema militarización y la necesidad de soldados. A partir de los años 20 , el aluvión inflacionario, la necesidad de mano de obra y la disminución de presión de las levas, habría borrado las diferencias, igualando los valores hacia abajo. En el caso tucumano, se igualan desde 1823 hasta 1833; en Buenos Aires, en cambio, a partir de los 30, la remuneración de los asalariados rurales saca ventaja a la de sus pares del ejército, distancia que se va a mantener en las siguientes décadas (Gelman \& Santilli, 2014, p. 102).

De igual forma, los estudios de Carina Frid (2015) sobre los salarios en Santa Fe durante el mismo periodo, abonan las tendencias generales que observáramos en la relación entre remuneraciones militares y privadas en Buenos Aires y en Tucumán. Más allá de las particularidades y ciclos propios de cada caso, teniendo en cuenta la evolución de los salarios y de la canasta de bienes que se reconstruyeron, es posible afirmar que tanto en Santa Fe como en Tucumán los salarios monetarios alcanzaron a cubrir, con mayor o menor margen, según el periodo, la subsistencia de solo uno o dos de los miembros del grupo familiar. Por otra parte, los datos para la provincia del litoral también dan cuenta de la brecha entre salarios de soldados y de peones (rurales y urbanos) que se extiende hasta comienzos de la década de 1830, cuando las distancias entre unos y otros se acortaron, aunque manteniendo siempre la ventaja de las retribuciones de los asalariados rurales sobre las de los militares de más baja graduación.

En suma, más allá de las diferencias en los derroteros salariales de ambos segmentos de asalariados en las tres provincias, podemos inferir que los salarios más bajos de la sociedad, percibidos por la mayor parte de los asalariados en ambas regiones, se seguían muy de cerca entre sí y estuvieron fuertemente afectados en su relación con la moneda y los shocks inflacionarios, ${ }^{10}$ a diferencia de los salarios de las otras categorías que pudieron hacer frente a las crisis económicas y mantener una capacidad adquisitiva por encima del nivel de subsistencia.

10 La escasez de brazos por el alistamiento militar (explicitada en las fuentes en reiteradas oportunidades) explicaría la subida de ambos en 1818. La crisis de la moneda federal podría tener relación con el incremento registrado en 1825 , mientras que el descenso del salario real observable entre 1825 y 1827 respondería al incremento generalizado de precios que se registró a mediados de la década. Asimismo, los años 30 se inician con una notable alza de los salarios reales que supera al salario nominal, movimiento que podría responder a la baja de precios registrada en 1831 y 1832. La subida de precios en 1833, producto de sequías y trastornos climáticos, marca, igualmente, una caída del salario real que no se reflejó con la misma intensidad en la curva del salario nominal. 


\section{CONCLUSIONES}

La primera evidencia que surge del procesamiento de los datos analizados es la amplitud de la escala salarial existente entre los cargos públicos y la gran distancia entre los sueldos de la cúpula dirigente (gobernador, ministros y jefes militares) respecto del resto de los cargos que componían la administración provincial.

Por otra parte, advertimos que la mayor proporción de trabajadores (que ocupaban los cargos que agrupamos en la tercera y cuarta categoría según su retribución mensual) no lograban cubrir con sus ingresos la canasta básica de subsistencia, aumentando aún más esta proporción si consideramos la canasta de manutención general, que solo podían solventar las dos primeras categorías de empleados (que comprendían a una minoría). ¿Cómo explicar este fenómeno? ¿Cómo subsistía la mayoría de la población tucumana que conformaba el universo de soldados y peones con ingresos por debajo del costo mínimo de la canasta de consumo? Además de la hipótesis respecto al perfil social de este segmento de asalariados (jóvenes y solteros), podríamos encontrar respuestas a este interrogante cuestionando algunos conceptos y herramientas de análisis utilizadas por la historiografía. En este sentido, habría que replantear el uso de la categoría "peón albañil" como representativa del trabajo asalariado urbano, así como revisar la simplificación y generalización de una misma canasta de consumo para todos los segmentos sociales o relativizar la utilidad del salario real como indicador válido de niveles de bienestar en sociedades preindustriales, entre otros aspectos.

Sin duda, el abordaje de los salarios en etapas pre-estadísticas o premodernas agrega al problema de las fuentes un verdadero desafío de interpretación, puesto que supone la incorporación de una serie de variables de análisis -como la porción de población que recibía sueldos, otros ingresos familiares no salariales, la composición metálica y no metálica de las retribuciones, entre otras- que, debido a la fragmentaria y escurridiza información de las fuentes del periodo, no siempre es posible determinar. De este modo, tal como aseguran Djenderedjian y Martirén, resulta indispensable definir el significado social del salario para un determinado momento y lugar, así como reformular su uso como herramienta útil para construir estándares de vida comparables entre regiones e, incluso, entre provincias dentro de una misma región (Djenderedjian \& Martirén, 2015a, 2015b). En efecto, entre fines del siglo XVIII y comienzos del XIX, el salario se encontraba menos 
vinculado a la idea de pago regular por la fuerza de trabajo que al sentido de un premio, retribución o recompensa (generalmente irregular y esporádica) por trabajos o tareas específicas de corta duración. Además, no se debe perder de vista que el salario era solo una parte de los ingresos de una familia o grupo doméstico, y no siempre la más importante. Por todo ello, para el periodo tardo-colonial y posindependiente no resultan de gran utilidad los datos brutos sobre salarios si no se contempla -más allá de los montos monetarios- su composición, modalidad de pago y la periodicidad del trabajo (Djenderedjian \& Martirén, 2016). Todo esto requiere de una ardua tarea empírica que permita recuperar los alcances del salario en el periodo y espacio bajo estudio y que los convierta en indicadores válidos de ser comparables con otros momentos y regiones, en términos de capacidad adquisitiva.

A pesar de las limitaciones en el alcance de los resultados aquí obtenidos y reconociendo que lo hasta aquí analizado es válido solo para un segmento de asalariados que, es sabido, no son representativos de todo el universo de trabajadores, es posible formular algunas reflexiones en torno al comportamiento de los salarios y la desigualdad entre los trabajadores de la administración provincial a partir del análisis de la evolución de las distancias relativas entre los diferentes cargos o categorías salariales.

La estimación de ratios de bienestar y capacidad adquisitiva de los diferentes rangos salariales en diferentes momentos del periodo permitió mensurar la desigualdad entre las diferentes categorías de trabajadores e identificar las tendencias divergentes en lo que a niveles de bienestar se refiere. Se detecta, de este modo, que los cargos con mayor remuneración experimentaron un sistemático incremento en su capacidad de consumo en las primeras décadas posindependientes, mientras que los de menor categoría vieron estancadas -y en el caso de los cargos de menor remuneración, disminuidas- las posibilidades de satisfacer sus necesidades básicas de subsistencia.

En suma, las primeras décadas de vida independiente significaron para el universo de empleados estatales de la ciudad "Cuna de la Independencia" un impacto diferencial que se tradujo en un marcado crecimiento del poder adquisitivo de los empleados más calificados, un paulatino incremento de la distancia salarial entre estos últimos y los menos calificados, así como un sostenido deterioro del bienestar de los asalariados comprendidos en los escalafones más bajos de la administración provincial. 
Finalmente, al comparar los resultados sobre los niveles de bienestar obtenidos para la categoría más baja de trabajadores en esta pequeña ciudad norteña con los de otras regiones del mismo espacio rioplatense, es preciso mencionar que Tucumán se encontraba entre las posiciones más bajas. Mientras que en 1835 Buenos Aires y Santa Fe registraban ratios de bienestar de 1,50 y 1,18, ${ }^{11}$ respectivamente, Tucumán se ubicaba muy por debajo de ellos, con un ratio de 0,63 hacia 1832.

Si bien aún no estamos en condiciones de afirmarlo -en tanto el universo salarial examinado en este trabajo se encuentra reducido al empleo público urbano-, podríamos formular a manera de hipótesis que los indicadores aquí analizados no hacen sino abonar la tesis de Jorge Gelman sobre los efectos económicos de la independencia, la cual sostiene que luego de 1810 las cosas cambiaron dramáticamente al producirse ritmos de crecimiento muy disímiles en las regiones, a la vez que un amplio conjunto de provincias permaneció estancado o en declive por largos periodos. El gran distanciamiento entre el crecimiento de Buenos Aires y el litoral respecto al de las regiones del interior y, sobre todo, el atraso del viejo Tucumán colonial, se explicaría, entonces, por el cambio de paradigma económico (Gelman, 2010).

\section{REFERENCIAS}

Allen, R., Murphy, T., \& Schneider, E. (2012). The Colonial Origins of the Divergence in the Americas: A Labor Market Approach. The Journal of Economic History, 72(4), 863-894.

Arroyo-Abad, L., Davies, E., \& Van Zenden, J. L. (2012). Between conquest and Independence: Real wages and demographic change in Spanish America, 1530-1820. Explorations in Economic History, 49(2), 149-166.

Arroyo-Abad, L. (2013). Inestabilidad, costo de vida y salarios reales en Venezuela en el siglo XIX. América Latina en la Historia Económica, 20(3), 114-137. http://dx.doi.org/10.18232/alhe.v20i3.551

Balán, J. (1976). Migraciones, mano de obra y formación de un proletariado rural en Tucumán, Argentina, 1870-1914. Demografía y economía, X(29), 201-229. http://dx.doi.org/10.24201/edu.v10i02.337

11 La ratio de bienestar para Buenos Aires fue estimada por Gelman y Santilli (2016) a partir del salario del albañil no calificado. Para Santa Fe, se calculó el welfare ratio a partir del salario promedio de peones, albañiles y soldados; datos volcados en los cuadros 1 y 2 del trabajo antes citado de Carina Frid (2016). 
Barba, F. (1999). Aproximación al estudio de los precios y salarios en Buenos Aires desde fines del siglo XVIII hasta 1860. La Plata, Argentina: Ediciones Universidad Nacional de la Plata.

Bascary, A. M. (1999). Familia y vida cotidiana. Tucumán a fines de la colonia. Tucumán/Sevilla: Editorial Universidad Pablo de Olavide y Facultad de Filosofía y Letras Universidad Nacional de Tucumán.

Bliss, H. W. (1973). Gastos e ingresos públicos de la provincia de Tucumán en el periodo 1822-1854. Tucumán: Instituto de Investigaciones de Historia Económica y Social, Facultad de Ciencias Económicas, Universidad Nacional de Tucumán.

Bragoni, B., \& Olguín, P. (2014). Salarios y precios en Mendoza durante la gran transformación, 1870-1914. Jornada de Debate: Propiedad, salarios y precios en la Argentina del siglo XIX, Ciudad de Buenos Aires.

Campi, D. (2002). Azúcary trabajo. Coacción y mercado laboral. Tucumán, 18561896. Tesis doctoral. Universidad Complutense de Madrid, España.

Campi, D. (2004). La evolución del salario real del peón azucarero en Tucumán (Argentina) en un contexto de coacción y salario arcaico (18811893). América Latina en la Historia Económica, 22, 105-128. http://dx. doi.org/10.18232/alhe.v11i2.344

Challú, A. E., \& Gómez-Galvarriato, A. (2015). Mexico's real wages in the age of the great divergence, 1730-1930. Revista de Historia Económica, 33(1), 83-122.

Coatsworth, J. H. (1992). Historia económica e Historia de los precios en Latinoamérica colonial. En L. Johnson \& E. Tandeter (eds.). Economías coloniales. Precios y salarios en América Latina, siglo XVIII (pp. 31-44). Buenos Aires: Fondo de Cultura Económica.

Correa-Deza, M. F., \& Campi, D. (2009). La evolución del salario real del peón azucarero tucumano, 1881-1927. En VIII Congresso Brasileiro de História Econômica e $9^{a}$ Conferência Internacional de História de Empresas. Associação Brasileira de Pesquisadores em História Econômica (ABPHE). Campinas, São Paulo.

Cuesta, M. (2007). Precios y mercados en buenos aires en el siglo XVIII. América Latina en la Historia Económica, 28, 27-58. http://dx.doi. org/10.18232/alhe.v14i2.314 
Cuesta, M. (2012). Precios y salarios en Buenos Aires durante la gran expansión (1850-1914). Revista de Instituciones, Ideas y Mercados, 56, 159179. http://www.eseade.edu.ar/files/riim/RIIM_56/riim56_cuesta.pdf.

Djenderedjian, J., \& Martirén, J. L. (2015a). Precios, producto agrario y niveles de vida en las fronteras rioplatenses, 1700-1810: una nueva mirada sobre el crecimiento económico tardocolonial. Revista de Historia Económica, 33(1), 123-152. https://doi.org/10.1017/S0212610915000051

Djenderedjian, J., \& Martirén, J. L. (2015b). Are salaries a so useful tool to build up comparable standards of living? Some caveats concerning salary elements, available currencies, debts and credit in pre-modern Rio de la Plata region, 1770-1830. In XVII World Economic History Congress. Kyoto, Japan.

Djenderedjian, J., \& Martirén, J. L. (2016). Measuring living standards. Some caveats concerning salary elements in pre-modern Rio de la Plata region, 1770-1830. En XV Congreso de Historia Agraria de la SEHA. Lisboa, Portugal.

Fandos, C., \& Parolo, M. P. (2014). Riqueza personal y rubros de inversión. Tucumán (Argentina), 1860-1870. América Latina en la Historia Económica, 21(2), 199-232. https://doi.org/10.18232/alhe.v21i2.573

Frid, C. (2016). La evolución de los salarios en una economía en crisis: Santa Fe en la primera mitad del siglo XIX. En Old and New Worlds: The Global Challenges of Rural History, International Conference. Lisbon, ISCTE-IUL, 27-30 January.

Frid, C. (2017). Precios y crisis en una economía rioplatense. Santa Fe (17901850). América Latina en la Historia Económica, 24(2), 59-92. http://dx. doi.org/10.18232/alhe.v24i2.746

Garavaglia, J. C. (2004). La economía rural en la campaña de Buenos Aires vista a través de sus precios (1756-1852). En R. Fradkin y J. C. Garavaglia (Comps.). En busca de un tiempo perdido. La economía de Buenos Aires en el país de la abundancia 1750-1865. Buenos Aires: Prometeo.

Gelman, J. (2010). La gran divergencia. Las economías regionales en Argentina después de la Independencia. En S. Bandieri (compiladora). La Historia Económica y los procesos de independencia en la América hispana (pp. 105-129). Buenos Aires: Prometeo. 
Gelman, J., \& Santilli, D. (2014a). Los salarios y la desigualdad en Buenos Aires, 1810-1870. América Latina en la Historia Económica, 21(3), 85-115. http://dx.doi.org/10.18232/alhe.v21i3.579

Gelman, J., \& Santilli, D. (2014b). Mar de fondo. Salarios, precios y los cambios en las condiciones de vida de los pobladores de Buenos Aires en una época convulsa, 1810-1870. En D. Santilli, J. Gelman \& R. Fradkin (compiladores). Rebeldes con Causa. Conflicto y movilización popular en la Argentina del siglo XIX. (pp. 121-147). Buenos Aires: Prometeo.

Gelman, J., \& Santilli, D. (2015). Salarios y precios de los factores en Buenos Aires, 1770-1880: una aproximación a la distribución funcional del ingreso en el largo plazo. Revista de Historia Económica, 33(1), 153-186. https://doi.org/10.1017/S0212610915000075

Gelman, J., \& Santilli, D. (2016). ¿El paraíso de los asalariados? La canasta de consumo y el nivel de vida de la plebe de Buenos Aires, siglos XVIII y XIX. En Old and New Worlds: The Global Challenges of Rural History. International Conference. Lisbon, ISCTE-IUL, 27-30 January.

Gelman, J., \& Santilli, D. (2018). Wages and standards of living in the 19th century from a comparative perspective. Consumption basket, Bare Bone Basket and welfare ratio in Buenos Aires, 1825-1849. Economic History Research, 14, 94-106. https://doi.org/10.1016/j.ihe.2016.09.001

Halperín-Donghi, T. (2010). Comentarios. En S. Bandieri (compiladora). La historia económica y los procesos de independencia en la América hispana (pp. 35-44). Buenos Aires: Prometeo

Johnson, L. (1990). Salarios, precios y costo de vida en el Buenos Aires colonial tardío. Boletín del Instituto de Historia Argentina y Americana Dr. Emilio Ravignani, 2, 133-157.

Leoni-Pinto, R. [1998] (2007). Tucumán y la región noroeste. Periodo 18101825. Tucumán: Universidad Nacional de Tucumán.

Llorca-Jaña, M., \& Navarrete-Montalvo, J. (2015). The real wages and living conditions of construction in Santiago de Chile during the later colonial period, 1788-1808. Economic History Research, 11, 80-90. http:// dx.doi.org/10.1016/j.ihe.2014.04.003

López-de-Albornoz, C. (2002). Los dueños de la tierra. Economía, sociedad y poder en Tucumán (1770-1820). Tucumán: Universidad Nacional de Tucumán. 
Maluquerde-Motes, J. (2013). La inflación en España. Un índice de precios de consumo, 1830-2012. Estudios de Historia Económica, 64, 1-146. https://studylib.es/doc/6601251/la-inflaci\%C3\%B3n-en-espa\%C3\%B1a.-un-\%C3\%ADndice-de-precios-de.

Moraes, M. I., \& Thul, F. (2017). Los salarios reales y el nivel de vida en una economía latinoamericana colonial: Montevideo entre 17601810. Revista de Historia Económica, 36(2), 185-213. doi:10.1017/ S021261091700012X

Nicolini, E., \& Parolo, M. P. (2009). La circulación de moneda en el norte argentino luego de la Independencia: el caso de Tucumán entre 1820 y 1850. Revista de Historia Económica, 27(1), 75-102

Novillo, J. (2006). La población negra en Tucumán (1800-1820). Con especial referencia a los cuarteles urbanos y a los curatos de Los Juárez y Río Chico (tesis de maestría). Facultad de Filosofía y Letras, Universidad Nacional de Tucumán, Argentina.

Parolo, M. P. (2008). Ni súplicas, ni ruegos. Las estrategias de subsistencia de los sectores populares en Tucumán en la primera mitad del siglo XIX. Rosario: Prohistoria.

Parolo, M. P. (2015a). Canastas de consumo y costos de subsistencia en Tucumán durante la primera mitad del siglo XIX. Revista Población \& Sociedad, 22(2), 27-59.

Parolo, M. P. (2015b). Las demandas de la guerra. Evolución y estructura de los gastos militares en Tucumán, 1816-1825. Prohistoria, 18(23), 21-46. http://www.redalyc.org/articulo.oa?id=380143531002

Parolo, M. P. (2016a). La construcción de la fiscalidad provincial en la primera mitad del siglo XIX. Tucumán, 1814-1854. En M. P. Parolo \& C. Herrera (coordinadoras). Estado, impuestos y contribuyentes. La construcción del sistema fiscal en Tucumán en el siglo XIX, PROHISTORIA, Rosario.

Parolo, M. P. (2016b). La evolución de los precios en Tucumán durante la primera mitad del Siglo XIX. Folia Histórica del Nordeste, 26, 96-124. http://dx.doi.org/10.30972/fhn.0312913

Parolo, M. P. (2019a). Ganarse la vida en tiempos de guerra. Los salarios en Tucumán en la primera mitad del siglo XIX. Quinto Sol, 23(2), 1-23. http://dx.doi.org/10.19137/qs.v23i2.2708

Parolo, M. P. (2019b). Los desafíos teóricos y metodológicos en la construcción y estimación de canastas de subsistencia. El caso de la ciudad de 
Tucumán (Argentina) durante el siglo XIX. En IV Congreso de Historia Económica de la APHE. Agosto 5-7, Universidad de Piura, Perú.

Parolo, M. P., \& Fandos, C. (2011). Tierra, ganado y giro comercial. La distribución de la riqueza en la "próspera"Tucumán de la década de 1860. En J. Gelman \& D. Santilli (compiladores). El mapa de la desigualdad en Argentina, siglo XIX (pp. 261-301). Rosario: Prohistoria.

Riveros, L. A. (1987). Evolución de los precios en el siglo XIX. Estudios Públicos, 27, 257-292. https://www.cepchile.cl/cep/site/artic/20160303/ asocfile/20160303184238/rev27_riveros.pdf.

Schleh, E. (1956). Los salarios en la Industria Azucarera. Revista de La Industria Azucarera, LXI(750), n.d.

Vence-Conti, A., \& Cuesta, E. M. (2016). Prices and Wages in the 1890 Crisis in Buenos Aires. Revista de Historia Económica, March, 1-28. https://doi. org/10.1017/S0212610915000257 


\section{Cuadro 1.}

Ramos de gasto público por etapas. Tucumán, 1816-1854

\begin{tabular}{|c|c|c|}
\hline Ramos & 1816-1839 & 1840-1854 \\
\hline Hacienda en común & Hacienda en común & \\
\hline Diezmos & Diezmos & \\
\hline \multirow{11}{*}{ Sueldos } & \multirow{2}{*}{ Políticos } & Gobierno \\
\hline & & Secretaría de gobierno \\
\hline & Hacienda & Hacienda \\
\hline & Militares & Militares $(1842-47 \mathrm{~s} / \mathrm{d})$ \\
\hline & & Justicia \\
\hline & & Policía \\
\hline & & Instrucción pública \\
\hline & & Imprenta \\
\hline & & Culto religioso \\
\hline & & Correos \\
\hline & & Secretaría de la legislatura \\
\hline \multirow{2}{*}{ Gastos de guerra } & Gastos de guerra & Gastos de guerra (1842-47 s/d) \\
\hline & Gastos extraordinarios de guerra & Gastos extraordinarios de guerra \\
\hline Empréstitos & Empréstitos & Empréstitos \\
\hline \multirow{22}{*}{ Otros gastos } & Depósito en dinero & Hacienda/tesorería (1841 en ad.) \\
\hline & Policía (desde 1827) & Departamento de Policía \\
\hline & Municipal de propios & Secretaría de gobierno \\
\hline & Gastos de aduana & Gastos de aduana \\
\hline & Gastos reservados (desde 1828) & Gastos reservados del gobierno \\
\hline & Gastos extraordinarios & Órdenes del gobierno para servicio público \\
\hline & Gastos de etiqueta (desde 1834) & Etiqueta \\
\hline & Censos & Censos \\
\hline & & Dpto. de justicia \\
\hline & & Reservados \\
\hline & & Secretaría de la legislatura \\
\hline & & Comisaría del ejército \\
\hline & & Varios \\
\hline & & Culto \\
\hline & & Instrucción pública \\
\hline & & Jefe del piquete \\
\hline & & Honorable junta \\
\hline & & Ministerio general \\
\hline & & Libranzas del gobierno (1842 en adelante) \\
\hline & & Guardas de aduana \\
\hline & & Papel sellado \\
\hline & & Receptores de campaña \\
\hline \multirow{3}{*}{$\begin{array}{l}\text { propia según } \\
\text { 1973) y libros } \\
\text { duría, Archivo }\end{array}$} & & Correos \\
\hline & & Gastos en obras públicas \\
\hline & & Recompensa de servicios \\
\hline
\end{tabular}

Fuente: Elaboración propia según datos de Bliss et al. (1973) y libros mayores de contaduría, Archivo Histórico de Tucumán, sección hacienda. 
Cuadro 2.

Salarios Nominales de empleados públicos de la provincia de Tucumán (mensuales en pesos plata de 8 reales)

\begin{tabular}{|c|c|c|c|c|c|c|c|c|c|}
\hline Cargos & 1816 & 1819 & 1823 & $1826 / 27$ & $1831 / 32$ & $1842 / 44$ & 1852 & 1854 & Promedio \\
\hline Gobernador & 250 & 250 & 250 & 250 & 250 & 250 & 250 & 250 & 250,0 \\
\hline Asesor, secretario o ministro general. & 175 & 100 & 125 & $(-)$ & 155 & 155 & 125 & 125 & 137,1 \\
\hline $\begin{array}{c}\text { Oficiales (general, coronel, teniente } \\
\text { coronel) }\end{array}$ & 137,5 & 154 & 81,6 & 100 & 76,4 & $(-)$ & $(-)$ & 75 & 104,1 \\
\hline $\begin{array}{c}\text { Tesorero o ministro general } \\
\text { Comandante de resguardo }\end{array}$ & 100 & 100 & 108 & 83,3 & 108,2 & 108,2 & 108,3 & 60 & 97,0 \\
\hline $\begin{array}{c}\text { Oficiales (mayor, capitán, teniente, } \\
\text { subteniente) }\end{array}$ & 59,2 & 36,1 & 36,2 & 40,3 & 33 & $(-)$ & 33 & 18,6 & 32,3 \\
\hline Ayudantes de gob. y hac. & $(-)$ & $(-)$ & 29,4 & $(-)$ & 25 & 25 & 30 & 32,4 & 28,4 \\
\hline Oficial 10/20 (hacienda) & 27,5 & 25 & 33 & $(-)$ & 25 & & 30 & $(-)$ & 28,1 \\
\hline Guarda aduana & 16 & 16 & $(-)$ & 16 & 16 & 16 & 16 & 16 & 16,0 \\
\hline Auxiliar de hacienda & 10 & 12 & 8 & 15 & 7,2 & 7,2 & $(-)$ & $(-)$ & 10,1 \\
\hline Porteros (hac. y gob.) & 16,6 & $(-)$ & 6 & $(-)$ & $(-)$ & $(-)$ & 8 & 8 & 9,7 \\
\hline $\begin{array}{c}\text { Sub-oficiales (sargento, cabo, clarín, } \\
\text { tambor) }\end{array}$ & $(-)$ & 8,1 & 9 & 8 & 7 & $(-)$ & 7,8 & 4,5 & 7,2 \\
\hline Ordenanzas (hac. y gob.) & 10 & 10 & 8 & 4 & 5 & 5 & 6 & 8 & 7,0 \\
\hline \begin{tabular}{c} 
Tropa (soldados) \\
\hline
\end{tabular} & 10 & 9 & 4 & 6 & 4 & $(-)$ & 6,6 & 3,5 & 6,1 \\
\hline
\end{tabular}

Fuente: Archivo Histórico de Tucumán (AHT). Sección Hacienda (SH). Planillas de pago de Salarios. Libros de Contaduría (Mayores y Manuales). Años 1816-1854.

Cuadro 3.

Salarios nominales promedios por categoría de empleo (en pesos plata de ocho reales)

\begin{tabular}{|c|c|c|c|c|c|c|c|c|c|}
\hline Rangos & $\mathbf{1 8 1 5 / 1 6}$ & $\mathbf{1 8 1 9}$ & $\mathbf{1 8 2 3}$ & $\mathbf{1 8 2 6 / 2 7}$ & $\mathbf{1 8 3 1 / 3 2}$ & $\mathbf{1 8 4 4}$ & $\mathbf{1 8 5 2}$ & $\mathbf{1 8 5 4}$ & Promedio \\
\hline $\begin{array}{c}\text { Gobernador/jefes militares/ } \\
\text { ministros }\end{array}$ & 165,6 & 151,0 & 141,5 & 144,3 & 147,0 & 171,7 & 161,0 & 127,0 & 151,1 \\
\hline Funcionarios de 1\%/ oficiales & 42,7 & 30,5 & 37,1 & 45,1 & 29,0 & 29,1 & 35,5 & 25,1 & 34,3 \\
\hline Ayudantes/guardas/ auxiliares & 13,0 & 14,0 & 8,0 & 15,5 & 11,6 & 11,6 & 16,0 & 16,0 & 13,2 \\
\hline $\begin{array}{c}\text { Porteros / ordenanzas / } \\
\text { suboficiales/ soldados }\end{array}$ & 12,2 & 9,0 & 6,7 & 6,0 & 5,3 & 5,0 & 7,0 & 6,0 & 7,1 \\
\hline
\end{tabular}

Fuente: Archivo Histórico de Tucumán (AHT). Sección Hacienda (SH). Planillas de pago de Salarios. Libros de Contaduría (Mayores y Manuales). Años 1816-1854.Años 1816-1854. 


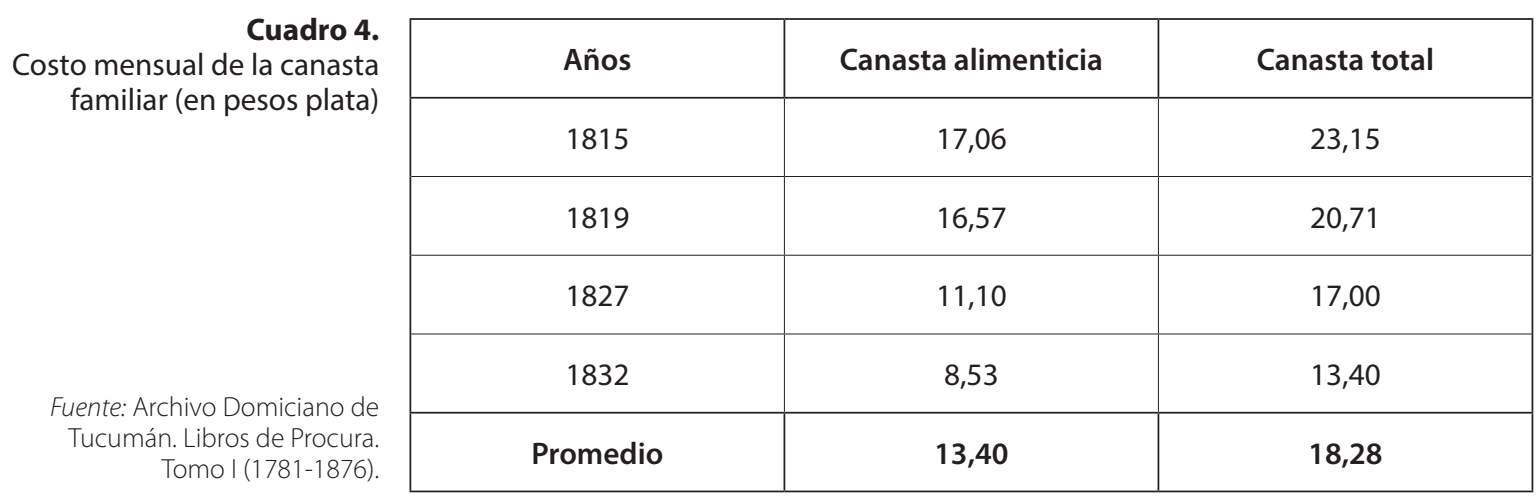

Cuadro 5.

Relación proporcional entre salarios máximos con el resto de las categorías

\begin{tabular}{|c|c|c|c|c|c|c|c|c|c|}
\hline Rangos & $\mathbf{1 8 1 5 - 1 6}$ & $\mathbf{1 8 1 9}$ & $\mathbf{1 8 2 3}$ & $\mathbf{1 8 2 6 / 2 7}$ & $\mathbf{1 8 3 1 / 1 8 3 2}$ & $\mathbf{1 8 4 2 / 4 4}$ & $\mathbf{1 8 5 2}$ & $\mathbf{1 8 5 4}$ & Promedio \\
\hline Categoría 1 / Categoría 2 & 3,9 & 4,9 & 3,8 & 3,2 & 5,1 & 5,9 & 4,5 & 5,0 & 4,4 \\
\hline Categoría 1 / Categoría 3 & 12,7 & 10,8 & 17,6 & 9,3 & 12,7 & 14,7 & 10,1 & 8,0 & 11,4 \\
\hline Categoría 1 / Categoría 4 & 13,6 & 16,7 & 20,9 & 24,1 & 27,6 & 34,2 & 22,7 & 21,3 & 21,1 \\
\hline
\end{tabular}

Fuente. Archivo Histórico de Tucumán (AHT). Sección Hacienda (SH). Planillas de pago de Salarios.

Libros de Contaduría (Mayores y Manuales). Años 1816-1854. 
Cuadro 6.

Salarios reales mensuales por categoría (en pesos plata de ocho reales)

\begin{tabular}{|c|c|c|c|c|c|c|c|c|c|}
\hline Rangos & $1815 / 16$ & 1819 & 1823 & $1826 / 27$ & $1831 / 32$ & 1844 & 1852 & 1854 & Promedio \\
\hline $\begin{array}{c}\text { Gdor. / Jefes Militares/ Ministros } \\
\text { Funcionarios de 1\%/ Oficiales } \\
\text { militares }\end{array}$ & 165,63 & 149,50 & 85,03 & 57,77 & 165,62 & 118,80 & 93,12 & 88,54 & 115,50 \\
\hline \begin{tabular}{c} 
Ayudantes / Guardas \\
\hline \begin{tabular}{c} 
Portero / Ordenanza / Soldado \\
\hline
\end{tabular}
\end{tabular} & 13,00 & 13,86 & 4,82 & 6,20 & 13,03 & 8,06 & 9,25 & 11,11 & 9,92 \\
\hline
\end{tabular}

Fuentes: Archivo Histórico de Tucumán (AHT). Sección Hacienda

(SH). Libros de Contaduría

(Mayores y Manuales).

Planillas de pago de Salarios y de Gastos de Guerra (precios de reses). Años 1816-1854.

Cuadro 7.

Ratios de bienestar por categoría (salario nominal/ canasta básica alimenticia por unidad familiar)

\begin{tabular}{|c|c|c|c|c|c|}
\hline Salarios nominales & $1815 / 16$ & 1819 & $1826 / 27$ & $1831 / 32$ & Promedio \\
\hline Gdor. / Jefes Militares/ Ministros & 9,71 & 9,11 & 13,01 & 17,28 & 10,97 \\
\hline Funcionarios de 1\%/ Oficiales militares & 2,51 & 1,84 & 4,07 & 3,41 & 2,46 \\
\hline Ayudantes / Guardas / Auxiliares & 0,76 & 0,84 & 1,40 & 1,36 & 0,99 \\
\hline Portero / Ordenanza / Suboficial / Soldado & 0,72 & 0,55 & 0,54 & 0,63 & 0,54 \\
\hline
\end{tabular}

Fuente: Archivo Histórico de Tucumán (AHT). Sección Hacienda (SH). Planillas de pago de Salarios. Libros de Contaduría (Mayores y Manuales). Años 1816-1854 y Archivo Domiciano de Tucumán. Libros de Procura. Tomo I (17811876). 
Cuadro 8.

Poder adquisitivo por categoría (salario nominal/ canasta total por unidad

familiar)

\begin{tabular}{|c|c|c|c|c|c|}
\hline Salarios nominales & $\mathbf{1 8 1 5 / 1 6}$ & $\mathbf{1 8 1 9}$ & $\mathbf{1 8 2 6 / 2 7}$ & $\mathbf{1 8 3 1 / 3 2}$ & Promedio \\
\hline Gdor. / Jefes Militares/ Ministros & 7,15 & 7,29 & 8,50 & 11,00 & 8,04 \\
\hline Funcionarios de 1\%/ Oficiales militares & 1,85 & 1,48 & 2,66 & 2,17 & 1,80 \\
\hline Ayudantes / Guardas / Auxiliares & 0,56 & 0,68 & 0,91 & 0,87 & 0,72 \\
\hline Portero / Ordenanza / Suboficial / Soldado & 0,53 & 0,44 & 0,35 & 0,40 & 0,39 \\
\hline
\end{tabular}

Fuente: Archivo Histórico de Tucumán (AHT, Sección Hacienda (SH), Libros de Contaduría (Mayores y Manuales), Planillas de pago de Salarios (1816-1854) y Archivo Domiciano de Tucumán, Libros de Procura, Tomo I (1781- 